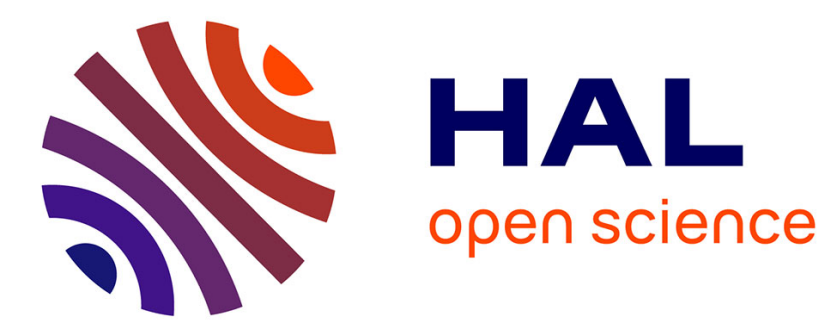

\title{
Determining radiated sound power of building structures by means of laser Doppler vibrometry
}

Nicolaas Bernardus Roozen, L. Labelle, Monika Rychtarikova, Christ Glorieux

\section{To cite this version:}

Nicolaas Bernardus Roozen, L. Labelle, Monika Rychtarikova, Christ Glorieux. Determining radiated sound power of building structures by means of laser Doppler vibrometry. Journal of Sound and Vibration, 2015, 346, pp.81-99. 10.1016/j.jsv.2015.02.029 . hal-02896213

\section{HAL Id: hal-02896213 https://hal.science/hal-02896213}

Submitted on $10 \mathrm{Jul} 2020$

HAL is a multi-disciplinary open access archive for the deposit and dissemination of scientific research documents, whether they are published or not. The documents may come from teaching and research institutions in France or abroad, or from public or private research centers.
L'archive ouverte pluridisciplinaire HAL, est destinée au dépôt et à la diffusion de documents scientifiques de niveau recherche, publiés ou non, émanant des établissements d'enseignement et de recherche français ou étrangers, des laboratoires publics ou privés. 


\title{
Determining radiated sound power of building structures by means of Laser Doppler vibrometry
}

\author{
N.B. Roozen ${ }^{\mathrm{a}, *}$, L. Labelle ${ }^{\mathrm{a}}$, M. Rychtárikováa,b ${ }^{\mathrm{a}}$, C. Glorieux ${ }^{\mathrm{a}}$ \\ ${ }^{a}$ Katholieke Universiteit Leuven, Laboratory of Acoustics, Soft Matter and Biophysics, \\ Department of Physics and Astronomy, Celestijnenlaan 200D 3001 Leuven, Belgium \\ ${ }^{b}$ STU Bratislava, Faculty of Civil Engineering, Department of Building Structures, \\ Radlinskeho 11, Bratislava, 813 68, Slovak Republic
}

\begin{abstract}
This paper introduces a methodology that makes use of laser Doppler vibrometry to assess the acoustic insulation performance of a building element. The sound power radated by the surface of the element is numerically determined from the vibrational pattern, offering an alternative for classical microphone measurements. Compared to the latter the proposed analysis is not sensitive to room acoustical effects. This allows the proposed methodology to be used at low frequencies, where the standardized microphone based approach suffers from a high uncertainty due to a low acoustic modal density.

Standardized measurements as well as laser Doppler vibrometry measurements and computations have been performed on two test panels, a lightweight wall and a gypsum block wall and are compared and discussed in this paper.

The proposed methodology offers an adequate solution for the assessment of the acoustic insulation of building elements at low frequencies. This is crucial in the framework of recent proposals of acoustic standards for measurement approaches and single number sound insulation performance ratings to take into account frequencies down to $50 \mathrm{~Hz}$.
\end{abstract}

Keywords: Radiated sound power, Sound reduction index, Laser Doppler vibrometer

PACS: 43.20.-f, 43.20.+g, 43.40.-r, 43.40.+s, 43.60.-c, 43.60.+d, 46.70.-p

\footnotetext{
*Corresponding author

Email address: bert.roozen@kuleuven.be (N.B. Roozen)
} 


\section{Introduction.}

The sound insulation quality of building elements is typically specified in terms of a frequency dependent sound reduction index $R(f)(\mathrm{dB})$, given in one-third octave bands in the frequency range of $100-3150 \mathrm{~Hz}$. Different single-number quantities, based on respective spectrum adaptation terms have been proposed and used for later communication between engineers, policy makers or other stakeholders. Among these are the ISO 717-1:2013 standard [1]. In Europe, often used descriptors are the weighted sound reduction index $R_{W}(\mathrm{~dB})$, the weighted apparent sound reduction index $R_{W}^{\prime}$ $(\mathrm{dB})$, the weighted standardized level difference $D_{n T, w}(\mathrm{~dB})$.

A standardized manner to determine the sound reduction index $R$ of a building element in laboratory conditions, is described in ISO 10140:2010 [2. It is known that the acoustic characteristics of the transmission suite can influence the measured sound reduction index [3, 4, 5, 6], especially at low frequencies. Driven by an increasing awareness of the importance of low frequencies in people's perception of the isolation performance of building elements, there is a growing need to extend the reliable frequency range of sound insulation measurements towards frequencies below $100 \mathrm{~Hz}$. However, at low frequencies, the sound reduction index is highly dependent on parameters such as the size of the testing chambers, the sound source location and the rooms surface absorption conditions [7], making it difficult to generalize test results to real-world situations. This uncertainty at low frequencies has two causes. One cause is that at low frequencies the spatial dependence of the pressure fields in the receiving room (and sending room) is high due to the finiteness of the room [8, 9, 10]. In practice, this causes inaccuracies in the measurement of the radiated sound power by means of microphones at a limited number of spatial positions. Another cause is the modal behavior of the receiving room, which influences the active sound power radiated by the vibrating wall (see for instance [3] and section 4.2.2 of this paper).

To assist the experimentalist with this problem, ISO 10140-4 includes an informative annex A, in which some guidance is given for improving the measurements in the low frequency range. The recommendations concern the spatial sampling of the sound field, the number of sources, the averaging time, and the minimum separation distances between the loudspeakers, the microphones and the surfaces of the test rooms. In a paper by Hopkins et al. [11] a modified measurement protocol was proposed in addition to the ISO standard, to reduce the measurement uncertainty for low frequencies. The 
fundamental problem, being the lack of diffusion of the sound fields in the low frequency range, however, remains.

In order to overcome the room acoustical complications that occur when measuring the sound field produced by a transmitting building element in a receiving room, a logical step is to try to measure the sound producing vibrations of the building element directly. In this paper the effectiveness of a Laser Doppler vibrometer (LDV) measurement technique was investigated for this purpose.

Laser Doppler vibrometer (LDV) techniques have been used for a large variety of applications, but mainly in structural dynamics [12], or in electroacoustics [13]. In relation to building acoustics, LDV has been successfully applied for the determination of the wall vibration in laboratory conditions. Sound transmission of windows has been investigated by Kaiser et al. [14] who have performed measurements and simulations of double glazing systems up to $1000 \mathrm{~Hz}$. A laser Doppler vibrometer was used to validate their numerical model. They showed that both the structural mode shapes and the resonance frequencies were in good accordance. Recently Churchill and Hopkins 15 used a scanning laser Doppler vibrometer for the measurement of the dynamic properties of a cross laminated timber plate, with emphasis on the analysis of structural eigenmodes.

In this paper the radiated sound power of a building element in a transmission suite is numerically determined from the vibrational response of the building element. The vibrational response is determined by means of advanced scanning LDV measurements. This approach is compared to the classical microphone based measurement methodology according to ISO 3741:2010. Special attention is given to the correspondence and differences at low frequencies, where the microphone approach is known to be strongly sensitive to effects caused by the lack of a diffuse sound field.

In Sec. 2 the different methodologies are outlined. Subsection 2.1 briefly deals with the standardized methodology to determine the transmitted sound power by means of microphone measurements according to ISO 10140. Subsection 2.2 gives an outline of the newly proposed methodology to determine the transmitted sound power from LDV measurement data. The discussion on the newly proposed methodology is subdivided into two parts, the first part (subsection 2.2.1) being the measurement of the vibrational response of the test wall by means of a scanning laser Doppler vibrometer. Special attention is given to the desirability of measuring points on the wall sequentially in time. This enables a large number of points to be measured. The 
second part (subsection 2.2.2 is devoted to the calculation of the radiated sound power from vibration measurements.

The proposed methodology is applied to two test walls. In section 3 the test set-up is described. In section 4 the measurement results are presented, in which first a discussion on the vibrational patterns of the test walls is presented (subsection 4.1), and secondly the determination of the radiated sound power is discussed (subsection 4.2). Conclusions are given in section 5

\section{Theory.}

In this section an outline of the laser Doppler and microphone methodologies are given.

\subsection{Determination of transmitted sound power according to ISO 10140.}

The most frequently used methodology to determine the sound reduction index of a building element mounted between the sending and receiving room of a measurement facility is prescribed in ISO 10140:2010. The methodology is based on microphone measurement data of the average sound pressure level in the sending $\left(L_{p 1}\right)$ and receiving room $\left(L_{p 2}\right)$, see Fig. 1. In order to account for the contribution of the reverberant sound to the total measured sound field in the receiving room, a correction term $10 \log (S / A)$ is added to the $\left(L_{p 1}-L_{p 2}\right)$ level difference, to obtain the sound reduction index $R$ :

$$
R=L_{p 1}-L_{p 2}+10 \log \left(\frac{S}{A}\right)
$$

where $S$ is the area of the free test opening in which the element is mounted, and $A$ the equivalent sound absorption in the receiving room (which can be determined from reverberation time measurements).

The sound reduction index can also be seen as the difference between the sound power level radiated into the receiving room, $L_{W}[\mathrm{~dB}$ ref. $1 p W]$, and the sound power level incident on the building element in the source room. The sound power level $L_{W}$ radiated into the receiving room is determined from the sound pressure level $L_{p 2}(f)$ [dB ref. $20 \mu \mathrm{Pa}$ ] in the receiving room 


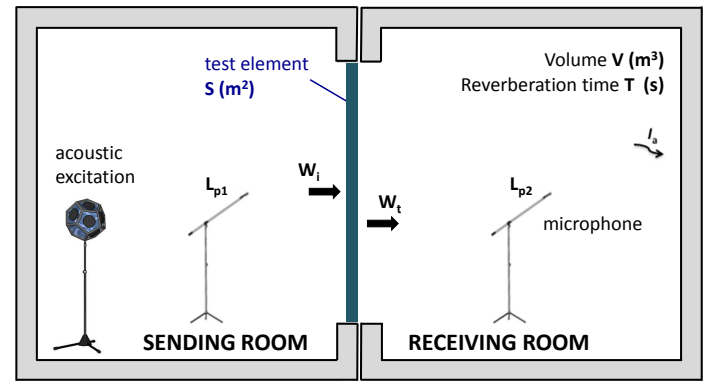

Figure 1: Classical measurement procedure to determine the sound reduction index of a building element in a transmission suite according to ISO 10140.

according to ISO 3741:2010 [16], assuming diffuse field conditions:

$$
\begin{aligned}
& L_{W}(f)= \\
& L_{p 2}(f)+10 \log \left(\frac{A}{A_{0}}\right)+4.34 \frac{A}{S}+10 \log \left(1+\frac{c S}{8 V f}\right)+C_{1}(f)+C_{2}(f)-6 \quad \mathrm{~dB}
\end{aligned}
$$

where $V\left[\mathrm{~m}^{3}\right]$ and $S\left[\mathrm{~m}^{2}\right]$ are the volume and surface area of the receiving room, $c\left[\mathrm{~ms}^{-1}\right]$ is the speed of sound, $f$ is the $1 / 3$ octave band center frequency, $A_{0}$ is the reference area of $1 \mathrm{~m}^{2}$ and $A$ is the acoustic absorption in the room in $\mathrm{m}^{2}$, which can be extracted from the reverberation time $T_{60}$ through

$$
A=24 \ln (10) \frac{V}{c T_{60}}=55.26 \frac{V}{c T_{60}}
$$

For the low frequency range of interest, the contribution of the term $4.34 \frac{A}{S}$, which was proposed by Vorländer to account for high frequency air absorption [17], as well as of the meteorological correction factors $C_{1}$ and $C_{2}$, is less than $1 \mathrm{~dB}$, so that the expression for $L_{w}$ can be simplified to

$$
L_{W}(f)=L_{p 2}(f)+10 \log \left(\frac{A}{A_{0}}\right)+10 \log \left(1+\frac{c S}{8 V f}\right)-6 \mathrm{~dB}
$$

Summarizing, the measurement procedure to determine the sound power level radiated into the receiving room, $L_{W}[\mathrm{~dB}$ ref. $1 \mathrm{pW}]$, involves 2 aspects. The first aspect is the measurement of the sound pressure level in the 


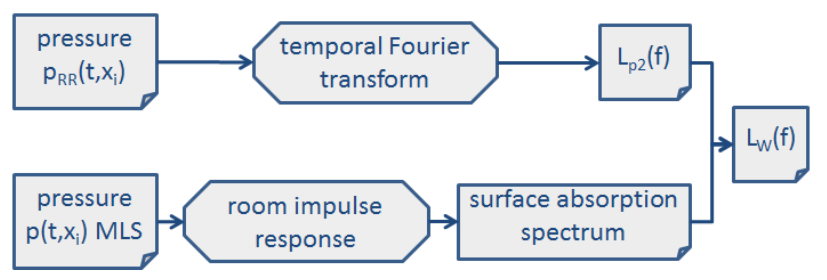

(a)

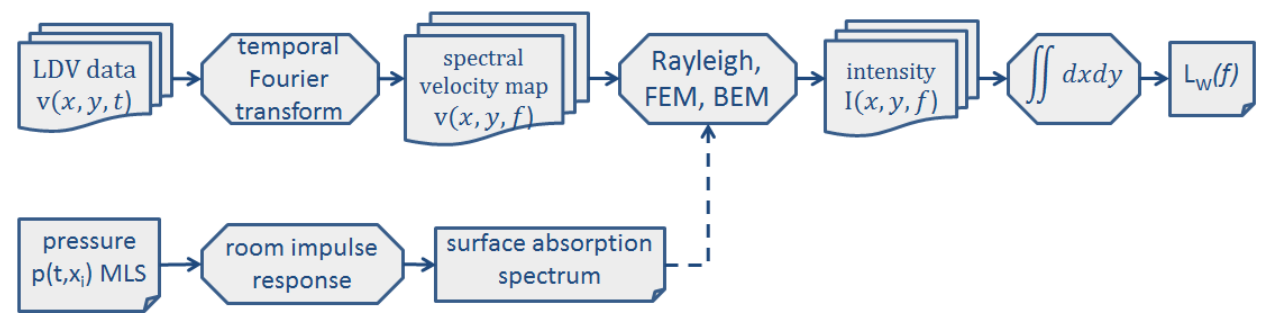

(c)

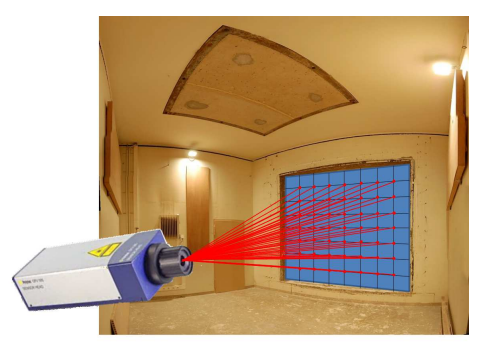

(b)

Figure 2: Methodologies to determine radiated sound power. (a) Microphone based ISO 10140. (b) Illustration of Laser Doppler based approach (c) Laser Doppler based approach.

receiving room, $L_{p 2}$, at a number of positions in the receiving room. The second aspect is the determination of the amount of absorption in the receiving room, denoted by the surface absorption spectrum, from reverberation measurements. The reverberation measurements involve the measurement of the impulse response of the room from an MLS or white noise response. This measurement methodology is depicted graphically in Figure 2(a).

\subsection{Determination of radiated sound power by Laser Doppler vibrometry.}

In this section a methodology is proposed to determine the radiated sound power from laser Doppler vibrometry measurements of the vibrating wall, as an alternative for the methodology described in ISO 3741:2010. The sound power, which is radiated by the vibrating wall into the receiving room is calculated from the measured vibration data by means of a numerical model. This can be either a Rayleigh integral model, a BEM model or a FEM model. To this end, the pressure on the surface of the vibrating wall is calculated 
with one of these models, which, when combined with the (known) velocity of the vibrating wall, yields the sound intensity in normal direction to the wall. Integrating the sound intensity across the wall gives the radiated sound power. Possibly, if a BEM or a FEM model is used, information about the absorption of the receiving room might be required. This measurement methodology is depicted graphically in Figure 2(c), and illustrated in Figure $2(\mathrm{~b})$.

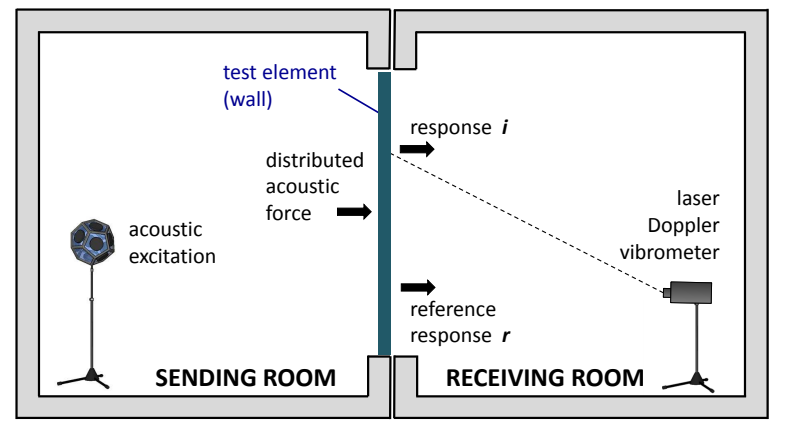

Figure 3: Laser Doppler vibrometry based measurement procedure to determine the radiated sound power of a building element in a transmission suite.

\subsubsection{Measurement of the vibrational response of the building element.}

In the proposed measurement scheme, the sound field in the source room is generated in the same way as in ISO2741:2010, by a loudspeaker producing an approximate pink noise spectrum. Although such excitation is quasi-random in time and space, the responses on different locations of the building element are correlated to each other. The responses can be decomposed in standing plate wave modes that satisfy the boundary conditions imposed by the panel mounting in the test opening between the sending and receiving room. We have exploited this spatial coherence in order to perform coherent averaging of the panel response as follows. The vibrational response of the panel at a grid of locations along its surface was measured by scanning the LDV probing spot sequentially over time across every point of the grid. In order to keep temporal coherence between measurements at different locations $i$, a multipass scheme [18] was followed. Every LDV data acquisition was accompanied by a synchronized recording of the vibrational response at one reference point $r$ of the panel (Fig. 3). In view of only one laser Doppler 
instrument being available, the reference measurement was done by an accelerometer at a fixed position. In order to obtain an accurate estimate of the spatially coherent response of the wall, the required measurement record length needs to be longer than the (mechanical or acoustical) reverberation time of the acousto-mechanical system involved [19].

The frequency response function between the response of the structure functions $H_{r i}$, at point $i$, as measured by the LDV, relative to the reference signal $r$, can be estimated using the optimal estimate [20]:

$$
H_{i r}(\omega)=\frac{S_{i r}(\omega)}{S_{r r}(\omega)}
$$

where the cross-spectra between the response of the structure at $N$ different positions and the reference signal are denoted by $S_{i r}(\omega)$, and the autospectrum of the reference signal by $S_{r r}(\omega) . \omega$ is the angular frequency. The estimates for $S_{i r}(\omega)$ contain the phase information between the responses at points $i$, with $i=1 \ldots N$ and the reference response at point $r$, from which the mutual phase differences between the responses at pairs of points $i$ and point $j$, with $i, j=1 \ldots N$, can be determined as

$$
H_{i j}(\omega)=\frac{S_{i r}(\omega)}{S_{j r}(\omega)}
$$

With the availability of $N$ measurement passes, it is advantageous to estimate the auto spectrum of the reference signal as follows [18]

$$
\left\langle S_{r r}\right\rangle_{N}=\frac{1}{N} \sum_{i=1}^{N} S_{r r(i)}
$$

yielding an improved signal to noise ratio as compared to each individual autospectrum $S_{r r(i)}$ (theoretically a factor $\sqrt{N}$ ) [19, 18]. In combination with the frequency response functions $H_{r i}$ for different locations $i$, the averaged structural response function $X_{i}$ at each individual point $i$, can be estimated as [18]:

$$
X_{i}=H_{r i} \sqrt{\left\langle S_{r r}\right\rangle_{N}}
$$

The ordinary coherence can be calculated as [20]

$$
\gamma_{r i}=\frac{\left|S_{r i}\right|^{2}}{S_{r r} S_{i i}}
$$


In the actual case of a multi-channel spectral analysis, it is advantageous to compute the global coherence $\gamma^{\text {global }}$, which considers all measurements simultaneously [19]:

$$
\gamma^{g l o b a l}=\frac{\left\langle\gamma_{r i} S_{i i}\right\rangle_{N}}{\left\langle S_{i i}\right\rangle_{N}}
$$

where $\langle. .\rangle_{N}$ denotes the average over all $N$ measurement points. The thus defined global coherence can be viewed as the ratio between the mean coherent autospectrum by the mean raw autospectrum.

\subsubsection{Calculation of the radiated sound power from vibration measurements.}

In order to calculate the radiated sound power from the LDV measured vibration data $X_{i}, i=1 \ldots N$ (Eq. 8), two approaches were used.

In the first approach the receiving room is assumed to be a semi-infinite acoustic domain to which the vibrating baffled test wall is radiating in a so-called Rayleigh integral model [21, 22, 23]. The acoustic pressure $p(\mathbf{r}, \omega)$ at position $\mathbf{r}$ in the acoustic domain, caused by the vibrating surface, is calculated as

$$
p(\mathbf{r}, \omega)=\frac{\mathrm{i} \omega \rho}{2 \pi} \iint_{S} v_{n}\left(\mathbf{r}_{\mathbf{S}}, \omega\right) \frac{e^{-\mathrm{i} k \mathcal{R}}}{\mathcal{R}} d S
$$

where $v_{n}\left(\mathbf{r}_{\mathbf{S}}, \omega\right)$ denotes the velocity in normal direction at position $\mathbf{r}_{\mathbf{S}}$ of the vibrating surface (e.g. $X_{i}$ in Eq. 8), $S$ denotes the area of the vibrating structure, $\mathcal{R}$ is the distance between $\mathbf{r}$ and $\mathbf{r}_{\mathbf{S}}, \rho$ is the density of air, $\omega$ is the angular frequency of the plate vibration, $c$ is the speed of sound in air, $k=\frac{\omega}{c}$ is the wave number, and $\mathrm{i}$ is the imaginary number. Since the normal component of the active acoustic intensity $I$ along the surface $S$ of a vibrating test wall, is given by

$$
I\left(\mathbf{r}_{\mathbf{S}}, \omega\right)=\frac{1}{2} \operatorname{Re}\left[p\left(\mathbf{r}_{\mathbf{S}}, \omega\right) v_{n}^{*}\left(\mathbf{r}_{\mathbf{S}}, \omega\right)\right]
$$

where Re denotes the real part of a complex quantity and the asterisk denotes the complex conjugate, the total radiated active sound power $P$ can be obtained by

$$
P(\omega)=\iint_{S} I\left(\mathbf{r}_{\mathbf{S}}, \omega\right) d S
$$

The computation of $p\left(\mathbf{r}_{\mathbf{S}}, \omega\right)$ involves a proper handling of the singularity in Eq. 11 when $\mathcal{R}=0$, which has been described in many text books (e.g. [24]). 
In an alternative approach, which takes into account the reverberant field in the receiving room, one can make use of the Boundary Element Method (BEM) [24] or the Finite Element Method (FEM) [25], by using the measured wall surface velocities at the scanned grid points in a multiplexed boundary condition. A discussion on the numerical efficiency of the BEM and FEM models is given in section 4.2.4.

When modeling the acoustics of the receiving room, the damping mechanisms need to be accounted for. Basically two damping mechanisms occur. It has been shown [26] for cases similar to the present one, that the effect of damping due to viscosity and thermal conduction within the boundary layers at the acoustic resonance peaks is less than $1 \mathrm{~dB}$, and even smaller at non-resonance frequencies. Damping effects occur also due to the absorption by the receiving and source room walls and the test wall, and due to interactions of the sound field with equipment (i.e. laservibrometer head, tripod, laservibrometer controller and computer) standing in the room.

A pragmatic way of dealing with damping is to extract effective damping parameter values from reverberation time measurements, and to incorporate them in an effective complex wavenumber, or, equivalently, a complex sound wave velocity:

$$
c=c_{0}(1+\mathrm{i} \xi)
$$

where $c_{0}$ is the speed of sound. The ratio of the imaginary part of $c$ to its real part, denoted by $\xi$, can be related to the reverberation time $T_{60}$ by (see Appendix A):

$$
\xi_{l m n}=\frac{\ln \left(10^{6}\right)}{2 \omega T_{60}} \approx \frac{1.1}{f T_{60}}
$$

\section{Measurement set-up.}

Experiments were performed in the transmission suite of the Laboratory of Acoustics of KU Leuven, consisting of two transmission rooms of almost identical shape, with a volume $\mathrm{V}$ of $88.78 \mathrm{~m}^{3}$ each and a total interior surface $S$ of $121.15 \mathrm{~m}^{2}$ each. The sending and receiving room are separated by a slightly inclined test partition (see Fig. 4). The Schroeder frequency of the rooms is approximately $350[\mathrm{~Hz}]$.

Two building elements were measured, a lightweight double wall and a gypsum block wall.

The lightweight double wall, consisted of two gypsum board plates, each with a thickness of $15 \mathrm{~mm}$. The plates were separated by an air gap with a 


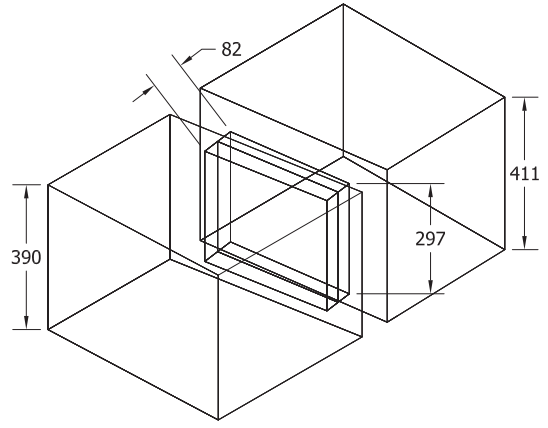

(a)

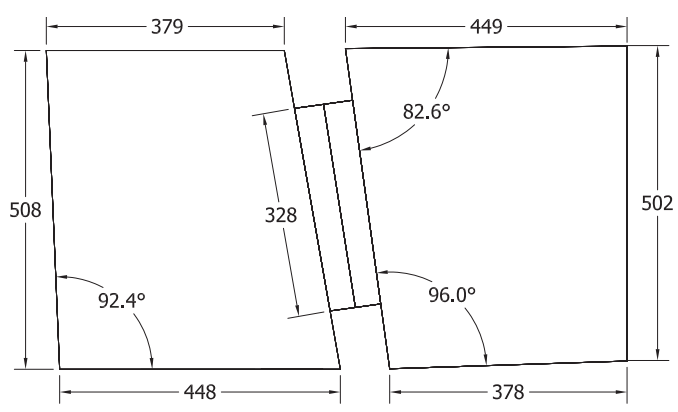

(b)

Figure 4: Dimensions of the transmission suite of the Laboratory of Acoustics of KU Leuven. Dimensions are given in $\mathrm{cm}$.

thickness of $75 \mathrm{~mm}$, which was filled with mineral wool. The double wall panel was supported by means of five vertically placed aluminum studs, placed in between the two gypsum board panels, every $60 \mathrm{~cm}$.

The gypsum block wall consisted of gypsum blocks of dimensions $666 \times$ $501 \times 100 \mathrm{~mm}$ (thickness $100 \mathrm{~mm}$ ), with a density of $930 \mathrm{kgm}^{-3}$. The test walls were excited by a sound field that was generated in the source room, by two sound sources emitting random pink noise, $95 \mathrm{~dB}$ in each $1 / 3^{\text {rd }}$ octave band. Two sound sources were used to have higher levels of sound power in the source room (resulting in a better signal to noise ratio, especially in the receiving room), and to create a better diffusion in the source room. The responses were measured by means of a scanning system, developed inhouse, which consists of a Polytec laser head OFV-505, a Polytec controller OFV-5000, and a dual-axis scanning mirror system from Thorlabs. Pieces of retro-reflecting tape were glued on the walls to increase the optical reflection at the measurement points, as shown in Fig. 5. The lightweight double wall was measured at both sides (i.e. at the source room and at the receiving room side of the partition). The measurement grid consisted of two interleaved rectangular grids; a grid of $9 \times 9$ and a grid of $8 \times 8$, making in total 145 measurement positions. In order to retain the phase information of the responses at different points, a reference signal was recorded simultaneously with the LDV signal. The reference signal was retrieved from an accelerometer (Bruel\&Kjaer type 4343 amplified with a Bruel\&Kjaer charge amplifier type 2635) which was placed at a fixed position on the test walls, approximately $20 \mathrm{~cm}$ from the bottom edge of the sending-side of the test 


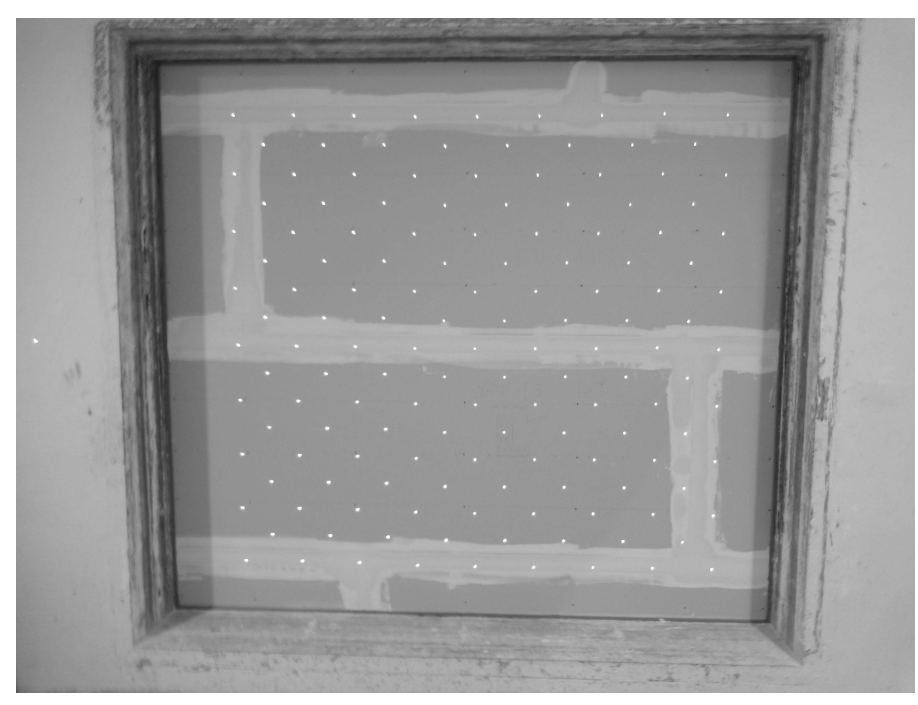

(a)

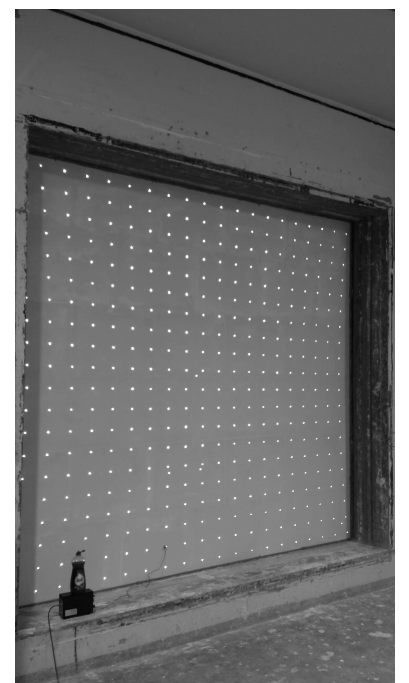

(b)

Figure 5: Test walls mounted in the transmission suite. (a) Lightweight double wall. (b) Gypsum block wall.

walls.

For the gypsum block wall, a grid of $20 \times 20$ was scanned, making in total 400 measurement points. The gypsum block wall was scanned at the receiving room side only. Phase information of the responses at different points was retained by measuring an accelerometer reference signal at the same position as for the lightweight double wall.

The interleaving grid that was used on the lightweight double wall can be considered as a normal rectangular grid (like was used on the gypsum block wall), which is rotated 45 degrees. The only important factor for grids, is the grid spacing. A courser grid limits the frequency range, whilst a more dense grids allows vibrations with a higher spatial frequency to be captured correctly. The grid spacing $d x$ of the interleaved grid (measured diagonally under an angle of 45 degrees) is $23 \mathrm{~cm}$, whilst the grid spacing $d x$ of the rectangular grid is $16 \mathrm{~cm}$. According to the Nyquist theorem, at least 2 samples per structural wavelength is required, meaning that the grid used for the gypsum brick wall and the lightweight double wall will be capable of capturing waves up to a wave number $k=\pi / d x=13\left(m^{-1}\right), k=\pi / d x=19$ $\left(m^{-1}\right)$, respectively.

In order to quantitatively assess effects of room acoustics on the acoustic 


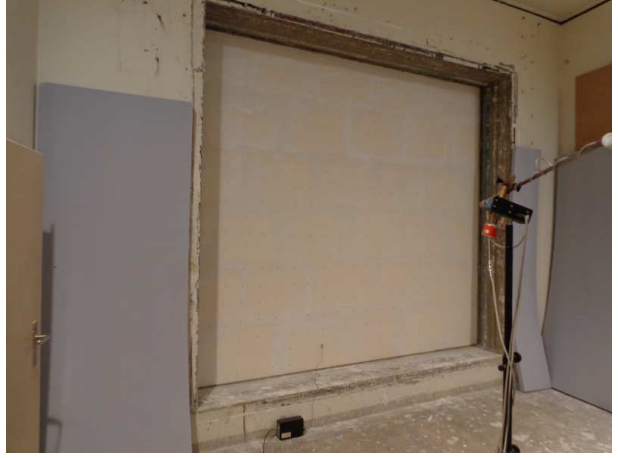

(a)

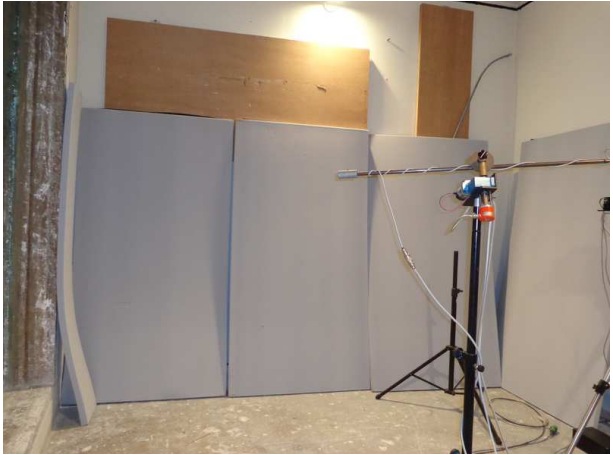

(b)

Figure 6: Receiving room with absorbing material (Melamine foam) placed in the room. (a) View on test-wall. (b) View on test facility wall.

field in the receiving room, for the gypsum block wall, LDV measurements and sound pressure measurements were performed with and without absorbing material in the receiving room. Large pieces of Melamine foam $(253 \times$ $133 \times 5 \mathrm{~cm}^{3}$ ) were placed against the walls of the receiving room (Fig. 6) in order to lower the reverberation time significantly.

\section{Measurement results.}

\subsection{Measurement of structural response of the test walls.}

In this section vibrational measurement results of the test walls are given, from which conclusions can be drawn with respect to signal to noise ratio issues (subsection 4.1.1), the influence of the acoustics of the receiving room on the vibrational level of the test wall (subsection 4.1.2) and the vibrational behavior of the test walls (subsection 4.1.3).

\subsubsection{Signal to noise ratio of laser Doppler measurements}

The vibrations of the test walls were measured using the approach outlined in Sec. 2.2, obtaining 145 frequency response functions for the lightweight double wall, and 400 frequency response functions for the gypsum block wall, using a measurement record length of $20 \mathrm{~s}$. This record length safely complies with the rule of thumb that the measurement record length needs to be longer than the (mechanical or acoustical) reverberation time of the acousto-mechanical system involved [19]. The velocity power spectral density $\left|X_{i}\right| / \sqrt{\Delta f}$, computed according to Eq. 8, with a frequency resolution 


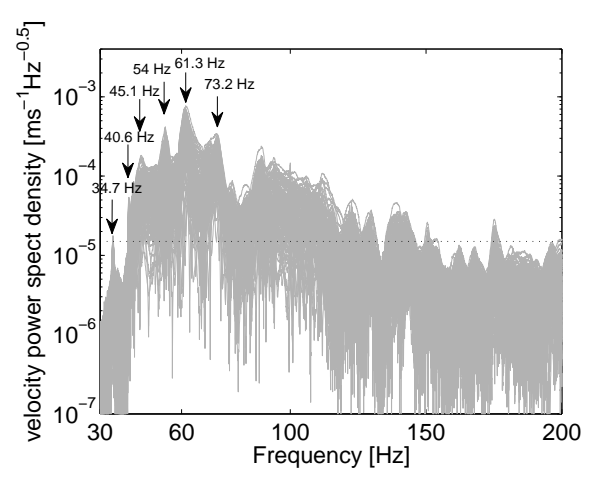

(a)

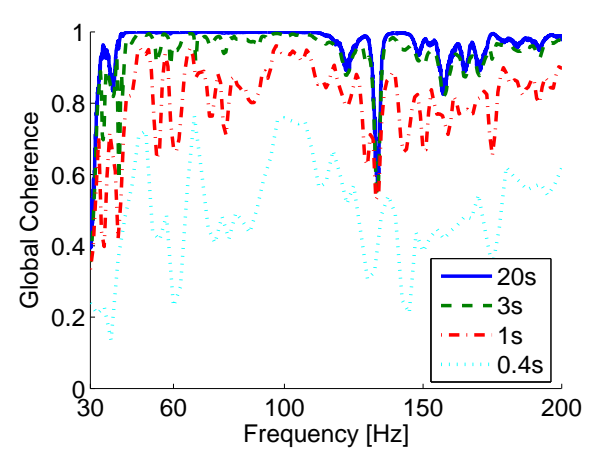

(c)

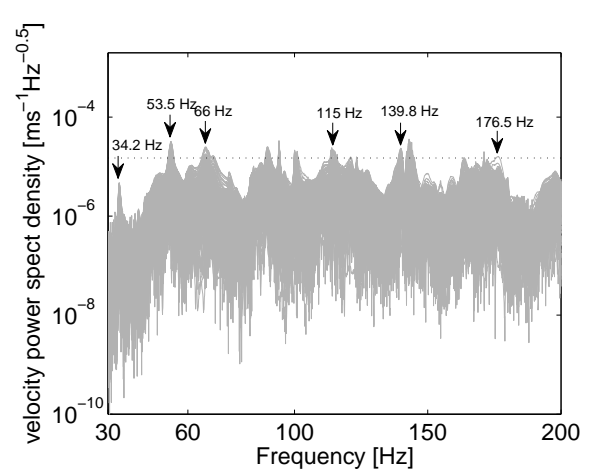

(b)

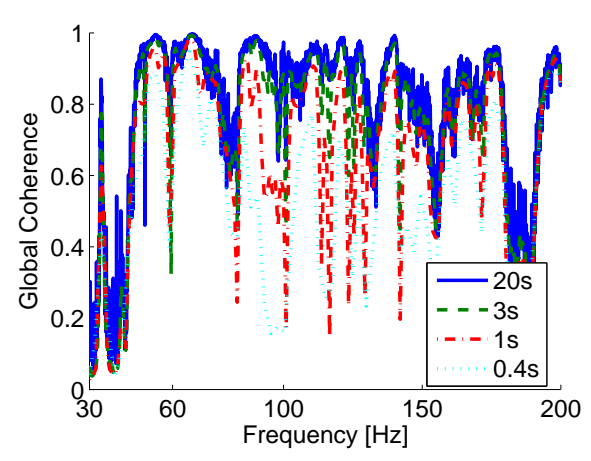

(d)

Figure 7: Velocity autopower spectra and global coherence. The dotted lines in the upper graphs show the power level below which the coherence is low. (a) Autopower spectrum of the lightweight wall, using a record length of $20 \mathrm{~s}$. (b) Autopower spectrum of the gypsum block wall, using a record length of $20 \mathrm{~s}$. (c) Global coherence of the lightweight wall, using different record lengths $(20 \mathrm{~s}, 3 \mathrm{~s}, 1 \mathrm{~s}, 0.4 \mathrm{~s})$; (d) Global coherence of the gypsum block wall, using different record lengths $(20 \mathrm{~s}, 3 \mathrm{~s}, 1 \mathrm{~s}, 0.4 \mathrm{~s})$.

$\Delta f=1 / T=0.05 \mathrm{~Hz}$, are shown in Fig. 7(a) and 7(b) for the lightweight double wall and for the gypsum block wall, respectively.

A limitation of laser Doppler vibrometry measurements is that the vibration level of the test wall needs to be high enough. As compared to for instance accelerometer measurements, LDV measurements suffer from a reduced signal to noise ratio, as will be illustrated below.

The global coherence [19] given by Eq. 10, is shown in Fig. 7(c) and Fig. 7(d) for the measurements on the lightweight double wall and on the gypsum block wall, respectively. At frequencies where the power spectral density of 


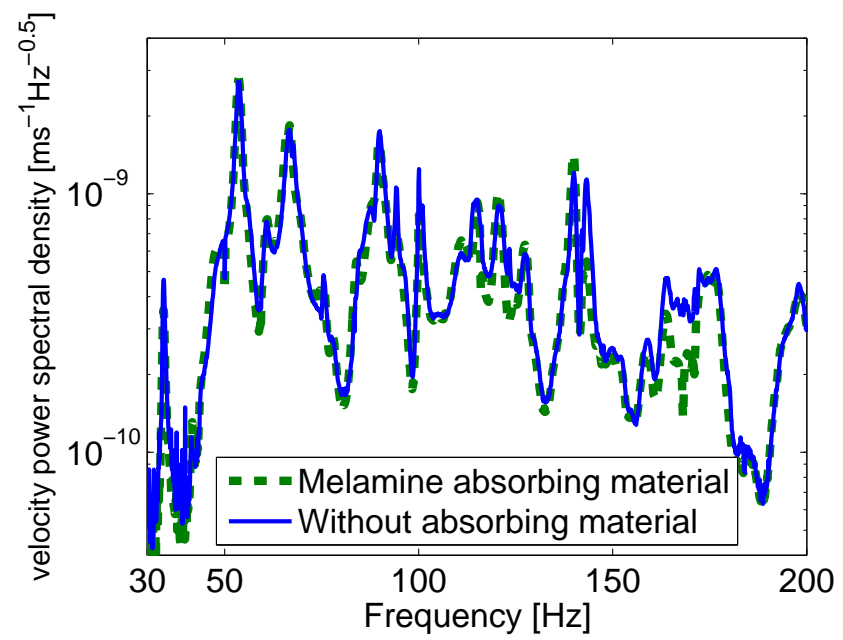

Figure 8: Mean power spectral density of gypsum block wall velocity. Solid curve: Receiving room without added absorbing material; Dashed curve: Receiving room with Melamine absorbing material added (for reverberation time with and without Melamine, see Fig. 13)

the vibrational response is below approximately $1.5 \cdot 10^{-5} \mathrm{~ms}^{-1} \mathrm{~Hz}^{-0.5}$, the global coherence is dropping, indicating a low signal-to-noise-ratio for this specific measurement device. Because the vibration level of the more heavy gypsum block wall is significantly lower as compared to the lightweight double wall (see Fig. 7(a) and Fig. 7(b) , the measurements on the lightweight double wall have an overall much better coherence as compared to the gypsum block wall.

The better coherence of measurements with a record length of 20 seconds as compared to the measurements with a shorter record length (e.g. 3, 1 or 0.4 seconds, as shown in Fig. 7(c), is in accordance with earlier findings [19, 27, 28] that the record length should preferably be equal or larger than the reverberation time of the sending or receiving room (see Fig. 13(a) for the typical reverberation time of the rooms).

\subsubsection{Invariability of the test wall vibration to changes in the acoustics of the receiving room}

Interestingly, putting absorbing material in the receiving room (see Fig. 13(b) for the measured reverberation time with and without absorbing material) does not noticeably change the structural vibration behavior of the gypsum block wall, as shown in Fig. 8. In the frequency range up to $100 \mathrm{~Hz}$, 


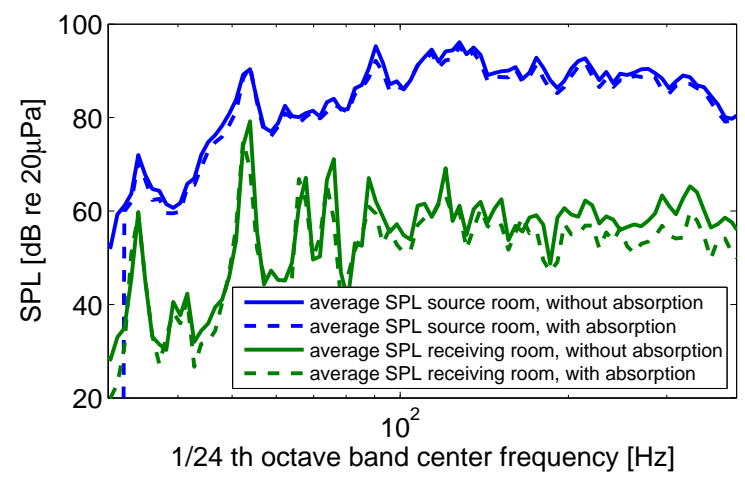

(a)

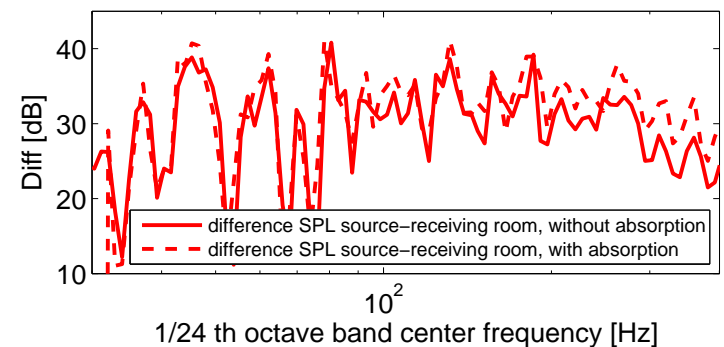

(b)

Figure 9: Sound pressure levels in the rooms during the gypsum block wall measurements. Solid lines: without absorbing material in the receiving room, dashed lines: with absorbing material in the receiving room (for reverberation time with and without absorbing material, see Fig. 13). (a) Mean sound pressure level in the source room and receiving room. (b) Difference in sound pressure level between source room and receiving room.

the peak vibration levels of the gypsum block wall do not change more than $1 \mathrm{~dB}$. At higher frequencies, the difference is somewhat larger. The reason for this is that, for this experiment, the sound pressure levels in the receiving room are 10 to $40 \mathrm{~dB}$ lower as compared to the sound pressure levels in the source room, as shown in Fig. 9. The structural response of the test wall is the combined response to acoustic excitation of the test wall from both the sending and receiving rooms. However, due to the large difference in sound pressure levels in the sending and receiving rooms, the exciting pressure in the source room is dominant in comparison to the exciting pressure in the receiving room. Even though changes of the room acoustics in the receiving room do affect the sound pressure level in the receiving room (see Fig. 9(a)), 
they only have a marginal effect on the structural response of the test wall.

\subsubsection{Dynamic behavior of test walls}

In Fig. 7(a) and 7(b) a number of structural resonance frequencies are indicated for which snapshots of the operational deflection shapes are shown in Fig. 10 and Fig. 11, respectively. Interestingly, for the lightweight double wall (Fig. 10), both sides of the double wall panel vibrate synchronously. As the thicknesses of the two panels are the same (in both cases $15 \mathrm{~mm}$ ), the dynamic behavior of both panels are similar. For this reason, and because of the aluminum studs which connect the two gypsum board panels, the two panels vibrate synchronously, especially at low frequencies. For frequencies of $73 \mathrm{~Hz}$ and above (see Fig. 10(f)), the vibrations are less synchronized. This is a result of structural uncertainties such as material properties, thickness variations and local imperfections becoming more apparent when the wavelength becomes shorter than the respective length scales.

According to the operational deflection shapes shown in Fig. 11, the outer boundaries of the gypsum block wall appear to vibrate freely at $x=0 \mathrm{~m}$, $x=3.27 \mathrm{~m}$ and at $y=2.98 \mathrm{~m}$, which are the 2 side edges and the top edge, respectively. At one edge, $y=0 \mathrm{~m}$, which is the bottom edge of the wall, the vibration levels are near to zero for all modes shown. Obviously, the weight of the wall and its connection at the bottom to the concrete walls of the test facility, prevent this edge to vibrate. Note that in practice the velocity is not measured exactly at the edge $y=0 \mathrm{~m}$, but approximately $1 \mathrm{~cm}$ higher, for practical reasons, which causes the measured vibration not to vanish completely. The other edges of the gypsum block wall are free (with a sealing between the gypsum block wall and the concrete walls of the test facility to prevent acoustic leaks).

Thus it can be concluded that the LDV measurements have the additional benefit in that it can identify the actual boundary conditions of a building element. Since the actual boundary conditions of walls are highly relevant for modeling and prediction, this can be useful.

Yet another additional benefit of LDV measurements is that the material properties of the device under test (i.e. the wall) can be determined, using dispersion analysis techniques. However, as this topic is not the focus of this paper, the reader is referred to [29]. 


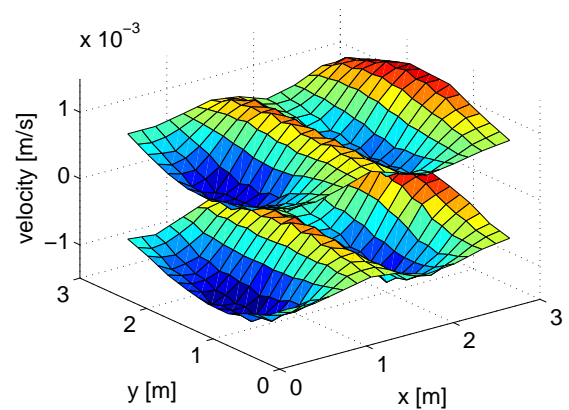

(a)

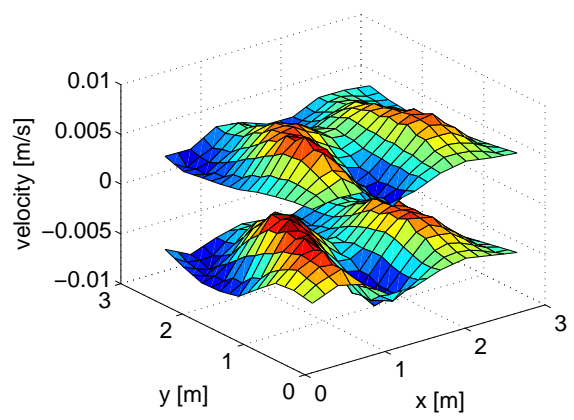

(c)

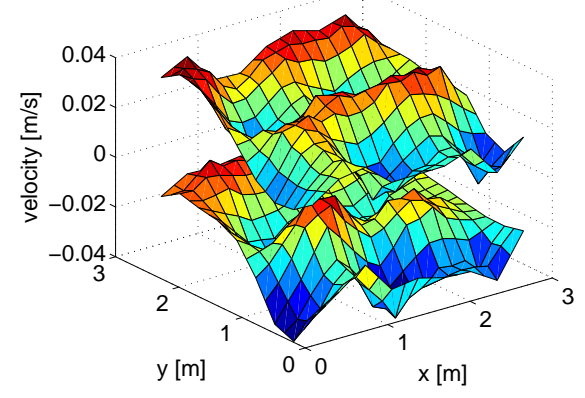

(e)

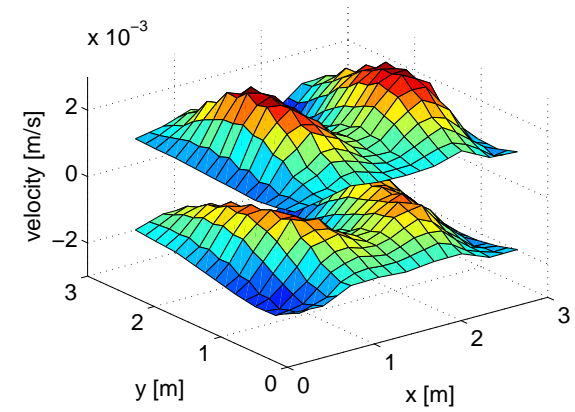

(b)

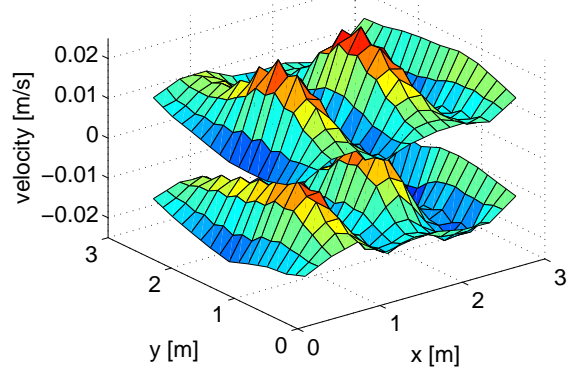

(d)

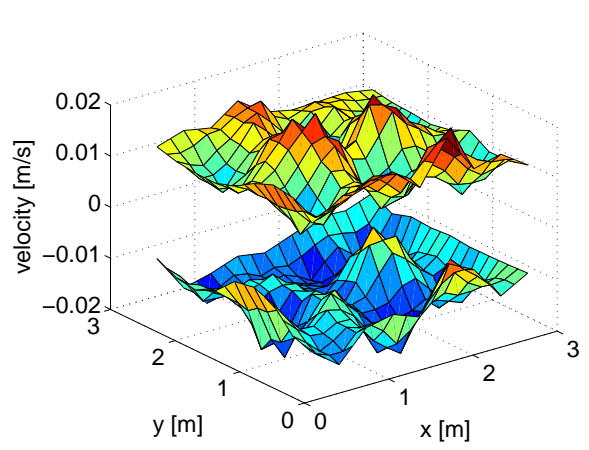

(f)

Figure 10: Operational deflection shapes of the lightweight double wall panel. Both the panel at the source room side (top) and the receiving room side (bottom) are shown. (a) $34.7 \mathrm{~Hz}$; (b) $40.6 \mathrm{~Hz}$; (c) $45.1 \mathrm{~Hz}$; (d) $54 \mathrm{~Hz}$; (e) $61.3 \mathrm{~Hz}$; (f) $73.2 \mathrm{~Hz}$. The selected frequencies correspond to the resonance peaks in Fig. $7(\mathrm{a})$ 


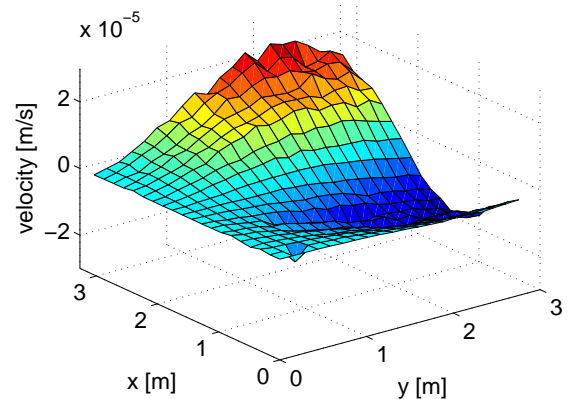

(a)

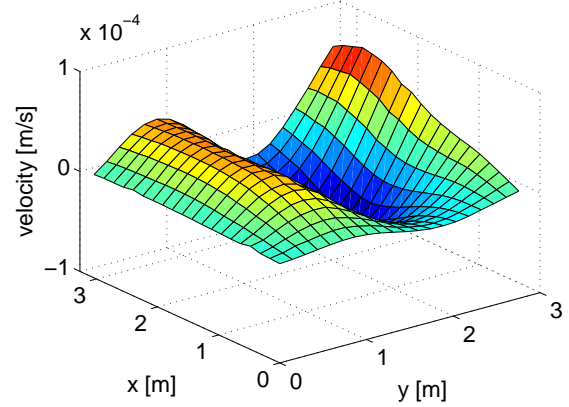

(c)

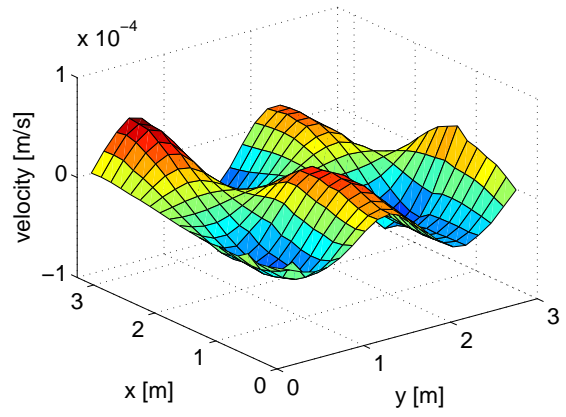

(e)

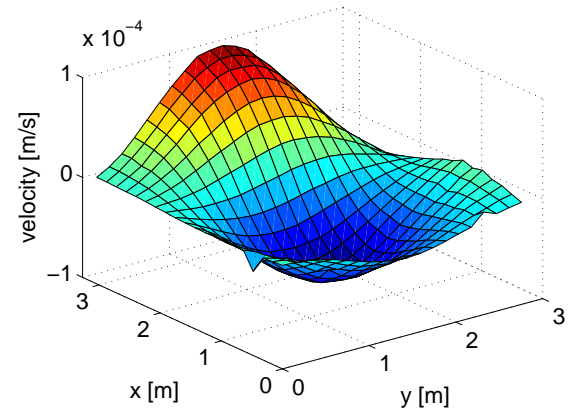

(b)

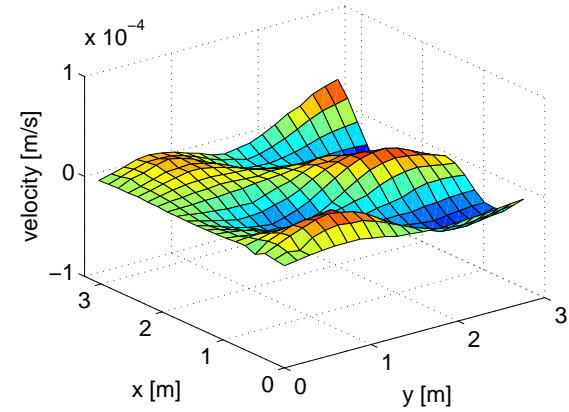

(d)

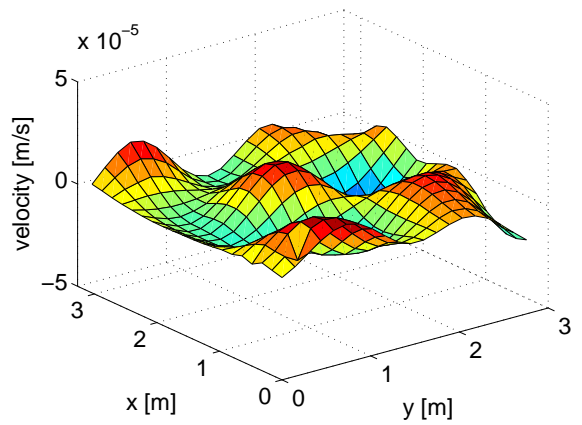

(f)

Figure 11: Operational deflection shapes of the gypsum block wall. (a) $34.2 \mathrm{~Hz}$; (b) 53.5 $\mathrm{Hz}$; (c) $66.1 \mathrm{~Hz}$; (d) $115.2 \mathrm{~Hz}$; (e) $139.8 \mathrm{~Hz}$; (f) $176.6 \mathrm{~Hz}$. The horizontal and vertical directions are along the $\mathrm{X}$ - and $\mathrm{Y}$-axis, respectively. The selected frequencies correspond to the resonance peaks in Fig. 7(b), 


\subsection{Sound power determination}

For both test walls, the lightweight double wall and the gypsum block wall, the radiated sound power was determined in the classical way (Sec. 4.2.1) and by means of LDV (Sec. 4.2.2).

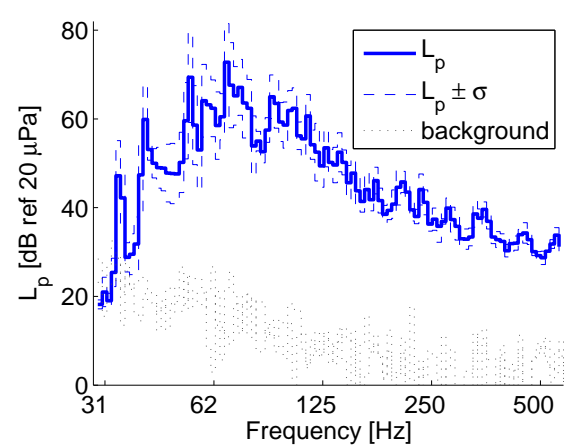

(a)

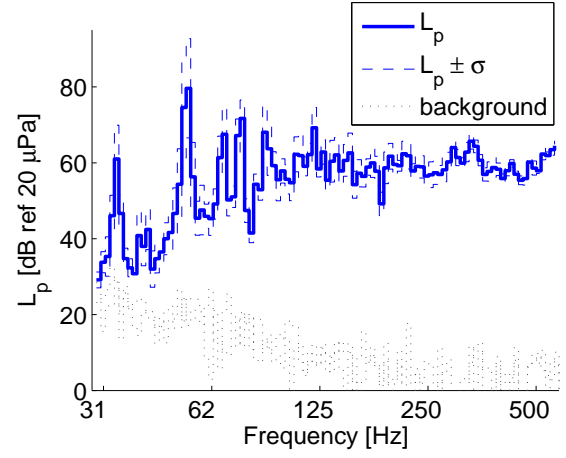

(b)

Figure 12: Sound pressure levels, averaged over 8 measurement positions in the receiving room, in $1 / 24^{\text {th }}$ octave bands. (a) Lightweight wall; (b) Gypsum block wall.

\subsubsection{Determination of radiated sound power by microphone measurements.}

The sound power radiated by the two test walls were determined by the classical methodology as outlined in Sec. 2.1. Sound pressure measurements were carried out at 8 uniformly spaced positions in the receiving room in $1 / 24^{\text {th }}$ octave bands, using a steady state pink noise acoustic excitation in the source room. The measurement results are shown in Fig. 12. The peaks in the measured sound pressure level are caused by structural resonances of the panel and acoustic resonances of the receiving room, as will be discussed in Section 4.2 .2 (Fig. 15). Fig. 12 shows that amongst the 8 microphone positions, the standard deviation of the measured sound pressure level is rather high, especially at low frequencies. For instance, for the lightweight double wall measurements, the standard deviation $\sigma$ is about $10 \mathrm{~dB}$ in the frequency range up to $80 \mathrm{~Hz}$, and for the gypsum block wall measurements even up to $15 \mathrm{~dB}$. At frequencies above $500 \mathrm{~Hz}$, the standard deviation drops to $1 \mathrm{~dB}$ or less. This observation on the standard deviation at low frequencies complies with literature (see the end of this section for a short discussion and references). 


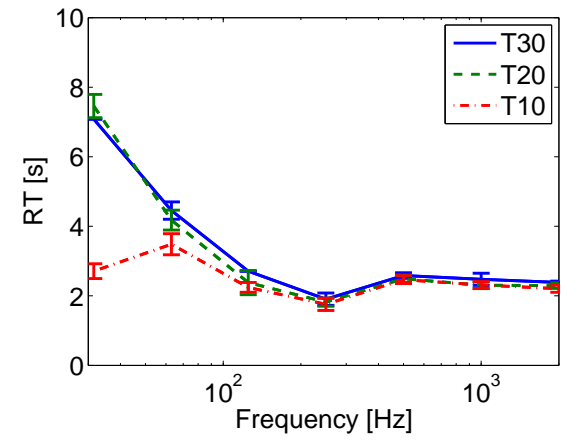

(a)

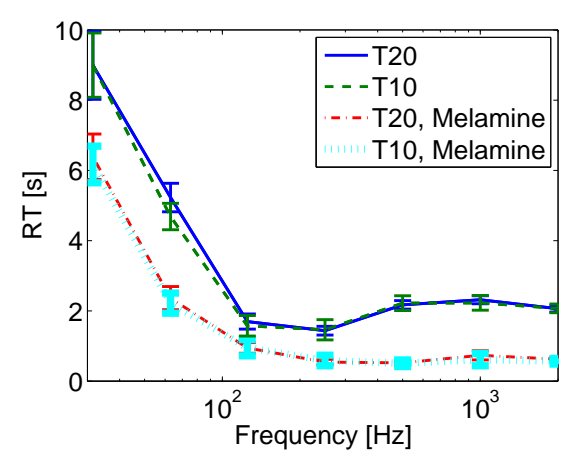

(b)

Figure 13: Measured reverberation time, in octave bands. Standard deviation $\sigma$ indicated by error bars. (a) $T_{10}, T_{20}$ and $T_{30}$ of receiving room for the lightweight wall measurements; (b) $T_{10}$ and $T_{20}$ of receiving room for the gypsum block wall measurements, with and without Melamine absorption material.

The measurement of the reverberation time $T_{60}$ of the receiving room was performed by impulse response measurements using an omni-directional point source B\&K 4295 and an omni-directional microphone B\&K 2642 on 19 receiver position, regularly distributed in the room following a grid of 80 x $80 \mathrm{~cm}$. The measurements were performed using an exponential sweep signal $(20-20000 \mathrm{~Hz}), 11$ seconds long. Reverberation time $\left(T_{10}, T_{20}\right.$ and $T_{30}$ ) was calculated from the measured room impulse responses (ISO 3282 [30]). Fits with a cross-correlation coefficient larger than 0.995 were used to determine the reverberation time and the standard deviation $\sigma$. Fits with a cross-correlation coefficient smaller than 0.995 were discarded.

Fig. 13 shows the frequency dependent reverberation time in the room. Separate reverberation time measurements were performed in the receiving room for the lightweight double wall mounted in the test opening, and the gypsum block wall mounted in the test opening. This was done in order to account for possible effects of the finishing of the test walls on the reverberation time in the receiving room. Some small differences in the reverberation time can indeed be seen.

At low frequencies, the slopes of the Schroeder curves are, unfortunately, significantly time-dependent due to an insufficient number of room modes at low frequencies, resulting in very different results for $T_{10}$ at one hand, and $T_{20}$ and $T_{30}$ on the other hand (see Fig. 13(a)). 


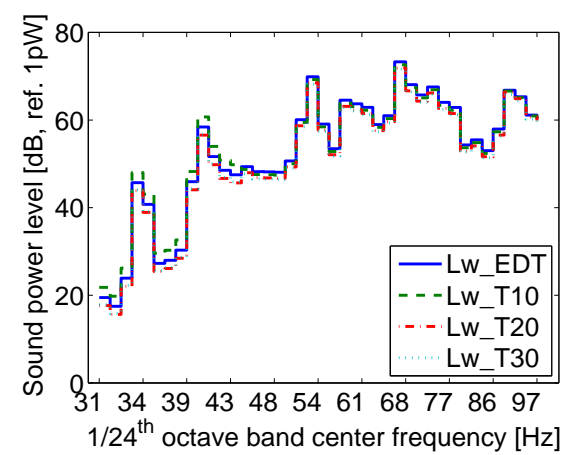

(a)

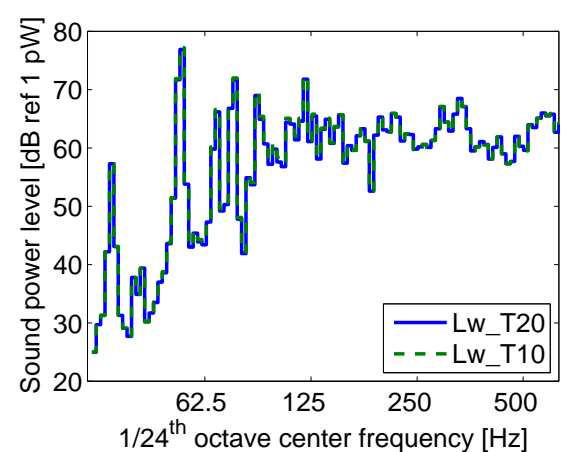

(b)

Figure 14: Active sound power level determined by classical methodology (based upon sound pressure and RT measurements, employing Eq. 4). (a) Lightweight wall; (b) Gypsum block wall.

Using the estimates of the reverberation time (Fig. 13) and the measured sound pressure levels (Fig. 12), the radiated sound power levels for the lightweight double wall and the gypsum block wall were calculated by means of Eq. 4, and shown in Fig. 14. The uncertainty in the reverberation time only marginally influences the computed sound power levels, with variations less than $0.3 \mathrm{~dB}$ when comparing $T_{20}$ and $T_{30}$-based estimates, and a maximum of $4 \mathrm{~dB}$ when comparing $T_{10}$ and $T_{20}$-based estimates.

It is well known that the uncertainty in the reverberation time at low frequencies, together with the standard deviation of the sound pressure measurements (with standard deviations up to $15 \mathrm{~dB}$ in the measurements presented in this work), results in a high uncertainty in the radiated sound power level estimates using the standardized approach [8, 9, 10].

In addition to the uncertainties that result from the limitations of the measurement technique, also the modal behavior of the receiving room creates an additional uncertainty. This uncertainty is related to changes in the receiving room dimensions (amongst different test facilities) and changes in the dynamics of the test wall [6, 5, 4, 3, 3.

The large uncertainty due to both measurement limitations and modal effects of the receiving room was our main incentive to apply the more robust, complementary LDV+Rayleigh approach for characterizing the sound insulation of building elements in the frequency range below $100 \mathrm{~Hz}$, which does not suffer from both types of uncertainties. 


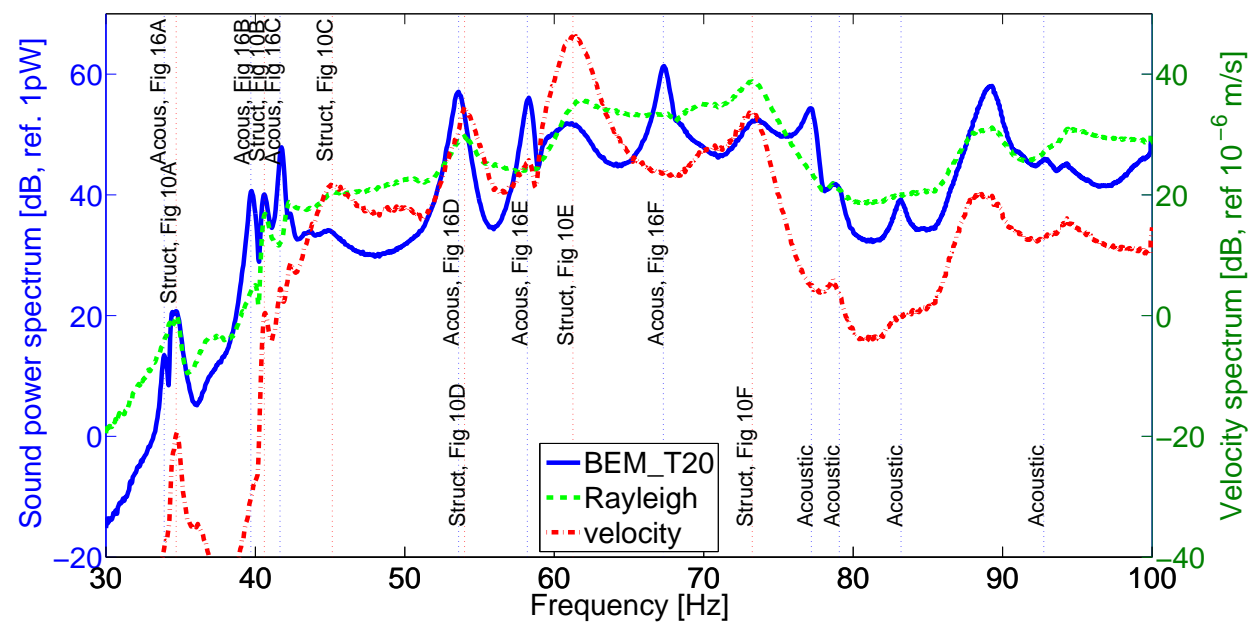

Figure 15: Radiated active sound power levels of the lightweight wall depicted in a spectrum with high resolution $(\Delta f=0.05 \mathrm{~Hz})$. Solid blue curve: BEM, damping parameter $\xi$ based on $T_{20}$. Dashed green curve: Rayleigh-integral. Dashed-dotted red curve: Spatially averaged velocity of test panel.

\subsubsection{Determination of radiated sound power by Laser Doppler vibrometry}

In this section the determination of the radiated sound power by means of LDV is discussed. For brevity, emphasis is put on a discussion of the narrow band computed sound power for the lightweight double wall, in this subsection. In Sec. 4.2 .3 the $1 / 24^{\text {th }}$ octave band results will be discussed for both test panels.

The radiated sound power was calculated from LDV measurement data, as discussed in Sec. 2.2.2, using BEM/FEM simulations and a Rayleigh integral approach. In particular, Eq. 13 is used to compute the active part of the radiated sound power. BEM simulations were performed for the lightweight double wall case, with a frequency resolution of $0.05 \mathrm{~Hz}$ (corresponding to the frequency resolution at which the LDV measurements were performed). This frequency resolution was more than sufficient to accurately capture the structural and acoustic resonances. Results of the BEM simulations are shown in Fig. 15. In the simulations a complex speed of sound was used, using $\xi$ values (see Eq. 15) based on the reverberation time measurements shown in Fig. 13(a), The values of the damping parameter $\xi$ for the lightweight wall are shown in Fig. A.20 (Appendix A). The narrowband estimates of the radiated active sound power which is based upon the Rayleigh integral, 


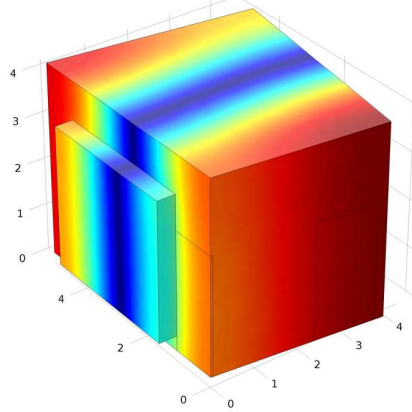

(a)

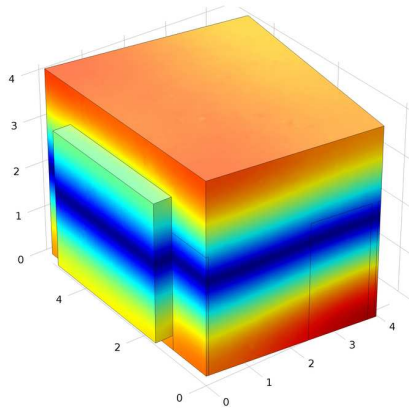

(c)

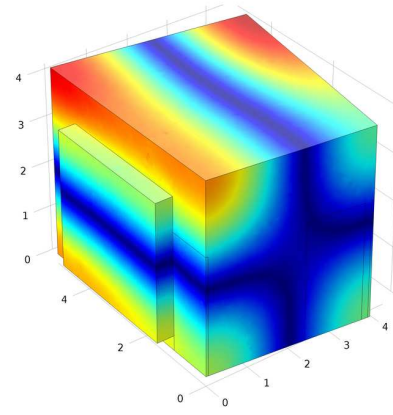

(e)

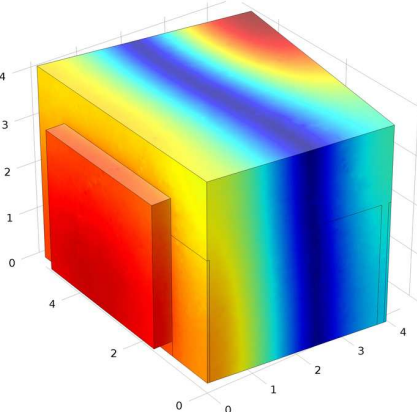

(b)

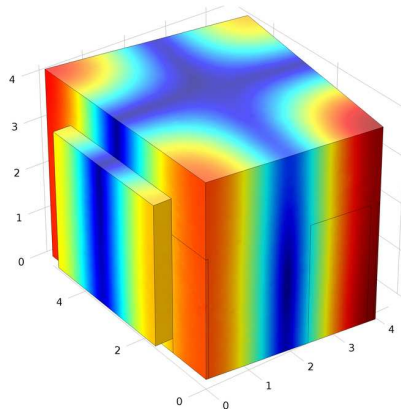

(d)

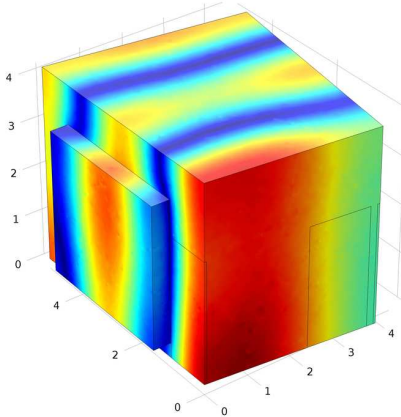

(f)

Figure 16: Acoustic eigenmodes of the receiving room, calculated by means of a FEM model. Red and blue colors denote a positive and negative pressure, respectively. The bulge on the front left of each plot corresponds with the location of the test panel. (a) $34.0 \mathrm{~Hz}$; (b) $39.1 \mathrm{~Hz}$; (c) $41.8 \mathrm{~Hz}$; (d) $53.4 \mathrm{~Hz}$; (e) $58.1 \mathrm{~Hz}$; (f) $66.9 \mathrm{~Hz}$. 


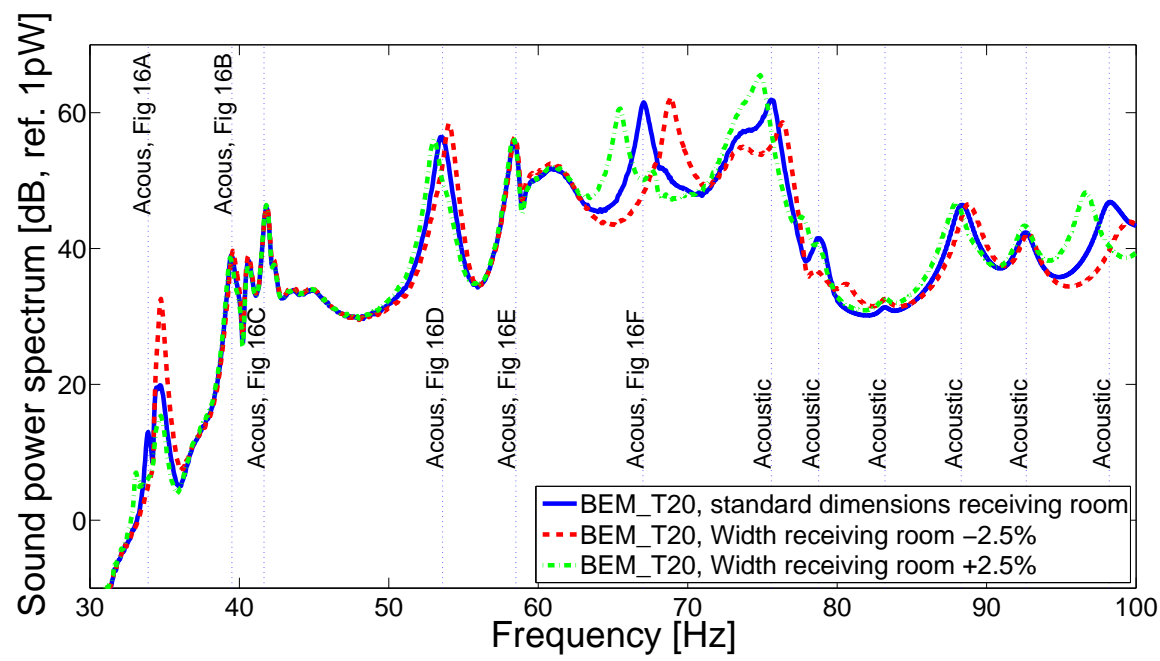

Figure 17: Radiated active sound power levels of the lightweight wall depicted in a spectrum with high resolution $(\Delta f=0.05 \mathrm{~Hz})$ for different width dimensions of the receiving room. Solid curve: standard dimensions receiving room. Dashed red curve: width decreased by $2.5 \%$. Dash-dotted green curves: width increased by $2.5 \%$.

employing Eq. 13, and the spatially averaged vibration spectrum of the test wall, are shown in Fig. 15 as well.

The differences in the sound power levels as estimated by the Rayleigh integral and BEM approach, clearly quantify the influence of the transmission suite due to modal effects of the receiving room. For instance, at a frequency of $66.8 \mathrm{~Hz}$, the BEM-model estimates a rather sharp peak in the sound power level, whilst the Rayleigh-integral does not show a peak. Many other examples of this situation can be found, e.g. at $33.5 \mathrm{~Hz}, 39.1 \mathrm{~Hz}, 41.2 \mathrm{~Hz}$, $53.1 \mathrm{~Hz}, 57.7 \mathrm{~Hz}, 78.6 \mathrm{~Hz}, 82.8 \mathrm{~Hz}$ and $92.2 \mathrm{~Hz}$, indicated in Fig. 15 by means of vertical dotted lines (in blue color). All these frequencies correspond to acoustic resonance frequencies of the receiving room. The eigenmodes of the receiving room up to $70 \mathrm{~Hz}$, as calculated by means of a FEM model, are presented in Fig. 16.

The active sound power that is radiated by the building element into the receiving room is larger at acoustic resonances of the receiving room. This is due to the fact that the acoustic impedance that is felt by the vibrating wall is much larger at acoustic resonance frequencies of the receiving room as compared to non-resonant frequencies. This causes the radiated active sound power of a panel to be dependent on the dimensions of the receiving 
room.

To study this effect in more detail, additional simulations were performed to calculate the radiated active sound power for different dimensions of the receiving room. Considering the eigenmodes of the receiving room (Fig. 16), it can be expected that the resonance frequency of the $53.4 \mathrm{~Hz}$ and $66.9 \mathrm{~Hz}$ acoustic resonances (Fig. 16(d) and Fig. 16(f), respectively) will be shifted to higher (lower) frequencies when reducing (increasing) the width of the room. Indeed, a $2.5 \%$ reduction (increase) of the width of the receiving room gives a shift of these resonance frequencies. It can also be seen that at these (shifted) resonance frequencies the radiated active sound power increases (see Fig. 17). This study confirms that the active sound power that is radiated by the building element into the receiving room is larger at the acoustic resonances of the receiving room, and that this increase shifts in frequency when the acoustic resonances of the receiving room are changed as a result of a change in room dimensions.

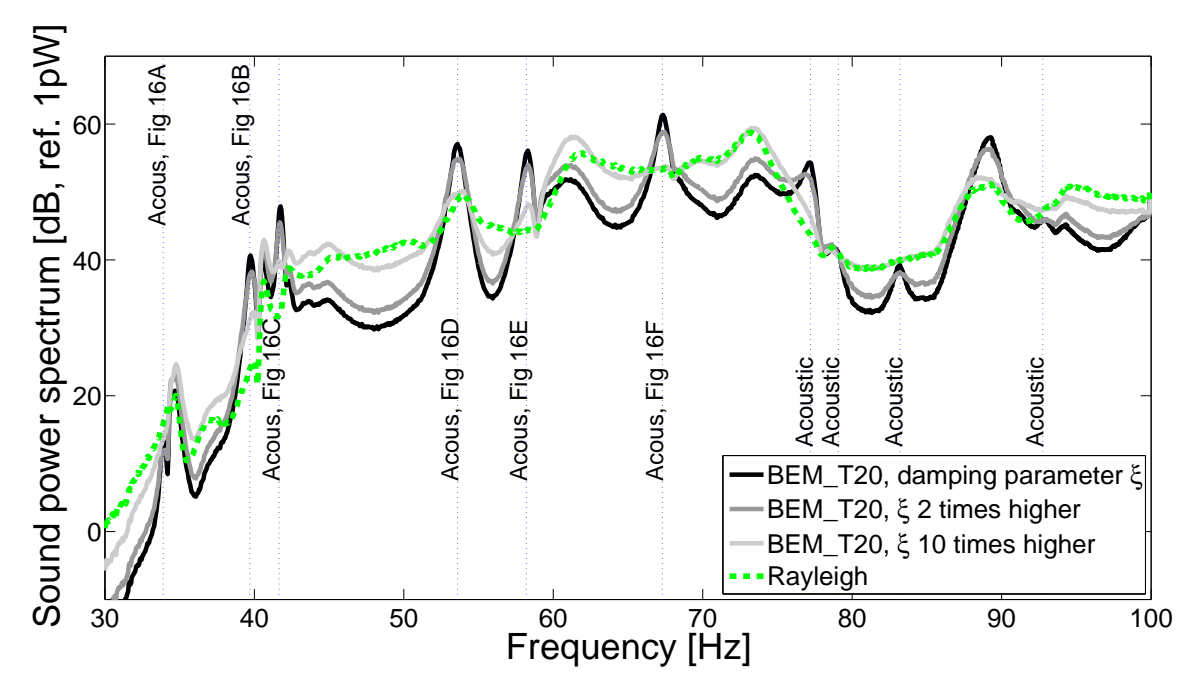

Figure 18: Radiated active sound power levels of the lightweight wall depicted in a spectrum with high resolution $(\Delta f=0.05 \mathrm{~Hz})$ for different values of the damping parameter $\xi$.. Solid black curve: BEM, calculation of damping parameter $\xi$ based on $T_{20}$. Solid gray curve: BEM, damping parameter $\xi$ multiplied by factor 2. Solid light gray curve: BEM, damping parameter $\xi$ multiplied by factor 10 . Dashed green curve: Rayleigh-integral.

Additional simulations were also performed to investigate the effect of absorption in the receiving room. The results, shown in Fig. 18, indicate that the larger the absorption, the lower the radiated active sound power at 
the acoustic resonance frequency of the receiving room, but the higher the radiated active sound power at non-resonant frequencies. From this figure it can also be seen that when increasing the sound absorption in the receiving room, the radiated active sound power converges to the free field case, as is simulated by the Rayleigh integral (dashed green curve in Fig. 18).

The structural resonances, as shown in Fig. 10, are indicated in Fig. 15 by means of vertical dotted lines (in red color). At the structural eigenfrequencies, both the radiated sound power as estimated by the Rayleigh integral (or the BEM method) and the spatial averaged velocity of the test panel show high responses.

Depending upon the coupling of structural panel modes and acoustic modes of the receiving room, the active sound power radiated by the test panel is significantly influenced. At low frequencies (in this study below $100 \mathrm{~Hz}$ ), the radiated active sound power tends to increase at the acoustic resonance frequencies of the receiving room, while the radiated active sound power decreases at non-resonant frequencies, as compared to the free-field radiation (calculated by means of the Rayleigh integral). An interesting way to exclude the effect of the acoustic modes of the receiving room is to calculate the radiated active sound power by means of a Rayleigh integral. This possibility makes the LDV approach a unique tool to determine the intrinsic sound transmission and insulation behavior of building elements, without being hampered by room acoustical effects.

\subsubsection{Comparison of laser Doppler vibrometry based sound power levels and conventionally determined sound power levels.}

In Fig. 19(a) the measured active sound power spectrum of the lightweight double wall, according to ISO 3741:2010, is compared with numerical estimates based upon the laser Doppler based approach. Both estimates based upon the Rayleigh integral (assuming free field radiation) and BEM are shown. For the computation of the active sound power levels by means of the BEM, the measured reverberation time $T_{20}$ was used for the determination of the imaginary part of the speed of sound, as discussed in Sec 2.2.2. For the classical ISO 3741 approach $T_{20}$ was used as well. Reverberation time determined from an interval of 20 or $30 \mathrm{~dB}$ were reported to be the most appropriate [31. The correspondence between the LDV-BEM-based estimate for the lightweight double wall and the classical ISO complying estimate is reasonably good.

In Fig. 19(b) the measured active sound power level of the gypsum block 


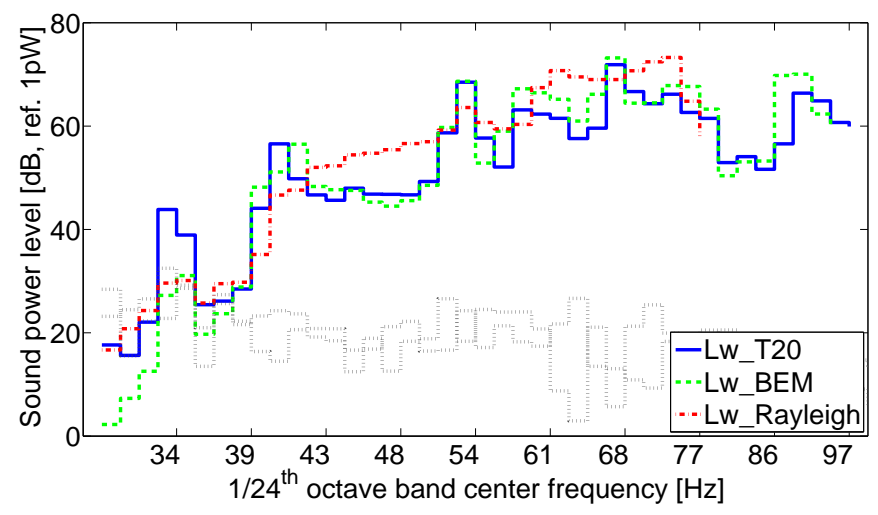

(a)

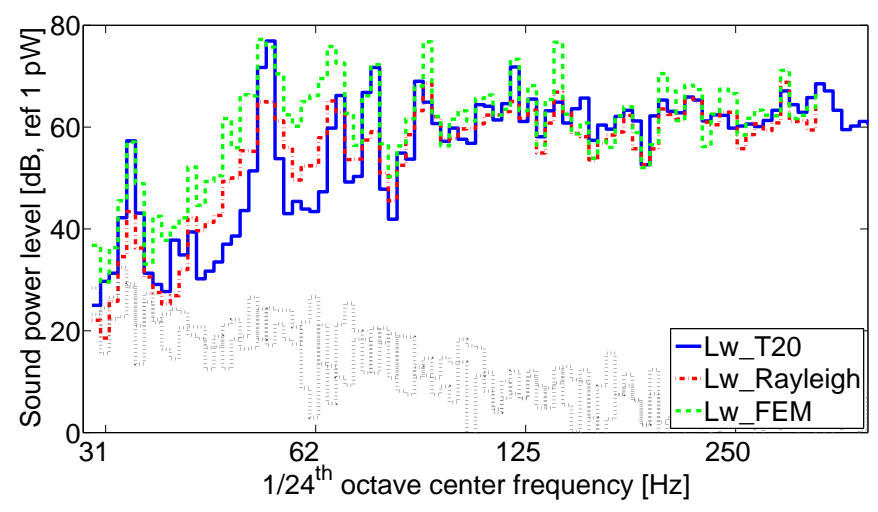

(b)

Figure 19: Active sound power estimates, in $1 / 24^{\text {th }}$ octave bands. Solid curve: Sound power level determined by classical methodologies (based upon sound pressure and RT measurements). Dashed curve: Sound power level determined by BEM/FEM simulations, using LDV measurement data and room acoustic damping based upon $T_{20}$ measurements. Dash-dotted curve: Sound power level determined by Rayleigh integral, using LDV measurement data. Dotted curves: background noise level. (a) Lightweight wall (BEM); (b) Gypsum block wall (FEM).

wall, according to ISO 3741:2010, is compared to the numerical estimates based upon the laser Doppler based approach. Again, the measured reverberation time $T_{20}$ was used for the classical approach. In this case a FEM model was used for the LDV-approach. The dissipation in the room was modeled by means of a complex speed of sound, as was done for the BEM model also, determining the imaginary part of the speed of sound from the 
measured reverberation time $T_{20}$, as discussed in Sec 2.2.2.

Also in this case the correspondence between the FEM-based estimate for the gypsum block wall and the classical ISO complying estimate is reasonably good. The Rayleigh-based approach gives much lower estimates of the radiated active sound power at frequencies which correspond to the acoustic resonances of the receiving room. This confirms earlier conclusions in this paper that, at low frequencies, the radiated active sound power increases at the acoustic resonance frequencies of the receiving room, as compared to the free-field radiation (calculated by means of the Rayleigh integral).

For frequencies above $250 \mathrm{~Hz}$, all estimates are converging. At these frequencies a sufficient number of acoustic modes are present in each $1 / 24^{\text {th }}$ octave band, which makes the acoustic field diffuse, and the influence of the room acoustics of the receiving mode small.

\subsubsection{Numerical efficiency considerations}

For the gypsum block wall, a FEM model of the receiving room was used consisting of approximately 220000 elements (about 90\% tetrahedral and $10 \%$ triangular) and 300000 nodes (thus also about 300000 degrees of freedom). The radiated sound power was computed from $0.98 \mathrm{~Hz}$ up to 343 $\mathrm{Hz}$, in steps of $0.49 \mathrm{~Hz}, 700$ frequencies in total. The computation time on a $3.4 \mathrm{GHz}$ Intel i7 computer was about 38 hours, requiring about 9 GBytes of physical memory.

For the lightweight double wall case, BEM simulations were performed. The model consisted of approximately 2200 triangular elements and 1100 nodes (thus also about 1100 degrees of freedom). The radiated sound power was computed from $30 \mathrm{~Hz}$ up to $80 \mathrm{~Hz}$, in steps of $0.05 \mathrm{~Hz}, 1001$ frequencies in total. The computation time on a $3.0 \mathrm{GHz}$ Intel Pentium computer was about 3 hours, requiring about 200 MBytes of physical memory.

It should be noted, however, that the mesh of the BEM model of the lightweight double wall was sufficiently fine to compute results up to about $90 \mathrm{~Hz}$, whilst the FEM model of the gypsum block wall was sufficiently fine up to a frequency of about $400 \mathrm{~Hz}$.

The evaluation of the Rayleigh integral for the gypsum block wall (from $0.98 \mathrm{~Hz}$ up to $343 \mathrm{~Hz}$, in steps of $0.49 \mathrm{~Hz}, 700$ frequencies in total) took about 15 minutes on $3.0 \mathrm{GHz}$ Intel Pentium computer, requiring about 50 MBytes of physical memory. For the lightweight double wall (from $30 \mathrm{~Hz}$ up to 80 $\mathrm{Hz}$, in steps of $0.05 \mathrm{~Hz}, 1001$ frequencies in total), it took about 20 minutes, and about 60 MBytes of physical memory. 
The BEM is computationally faster than FEM for this type of problem, as the number of degrees of freedom is significantly smaller (but the population of the system matrix is larger). The Rayleigh integral approach is by far the cheapest way to compute the radiated acoustic power.

\section{Conclusion.}

It was shown that the active sound power radiated by a vibrating wall at low frequencies can be determined without the influence of the acoustic modes of the receiving room of a transmission suite, using laser Doppler vibrometry (LDV). The radiated active sound power was calculated from the measurement data by means a Rayleigh integral. The methodology was demonstrated for two test walls, a lightweight double wall and a gypsum block wall.

Besides estimating the radiated active sound power by means of a Rayleigh integral approach, a Finite Element model (FEM) and Boundary Element model (BEM) were also used. The FEM/BEM approaches take into account the acoustic properties of the receiving room, which results in a deeper insight into the effects of standing waves in a non-diffuse sound field on the sound power radiated by the panel. Comparing the BEM-based estimates of the radiated active sound power to the Rayleigh-based estimates, it was shown that, depending upon the coupling of structural panel modes and acoustic modes of the receiving room, the active sound power radiated by the test panel can be significantly influenced. The radiated active sound power of the BEM-based estimate increases at the acoustic resonance frequencies of the receiving room by more than $10 \mathrm{~dB}$, whilst it decreases at non-resonant frequencies, as compared to the free-field radiation (calculated by means of the Rayleigh integral). This is due to the fact that the acoustic impedance that is felt by the vibrating wall is much larger at acoustic resonance frequencies of the receiving room as compared to non-resonant frequencies.

A crucial advantage of the LDV approach is that, by making use of a Rayleigh integral, the intrinsic sound transmission properties of a building element are obtained, independently of the particular properties of the test facility. In addition, uncertainties in the microphone based approaches caused by the spatially varying sound pressure levels at low frequencies as a result of the non-diffuse sound fields in the receiving room, were not encountered when using the LDV approach combined with the Rayleigh integral. 
The proposed methodology is complementary to the standardized, microphone based methodologies to determine the radiated sound power. The standardized methodology produces reliable estimates of the radiated active sound power at the higher frequencies, where the sound fields of the sending and receiving rooms are diffuse and where modal effects on the radiated active sound power averages out across the frequency bands. The LDV approach combined with the Rayleigh integral offers an alternative measurement tool for the lower frequencies, which does not suffer from the mentioned uncertainties.

Once having determined the intrinsic sound transmission properties of a building element by means of LDV, the acoustic radiation into any virtual room can numerically be computed by means of a suitable model (e.g. a FEM or a BEM model), to take into account the room acoustic effects of a particular application.

LDV measurements have the additional benefit in that it can identify the actual boundary conditions of a building element, which can be useful for modeling and prediction.

In order to cope with modal effects in the receiving room, which are not avoided by the present methodology, once can make use of a 2D loudspeaker array, combined with a feedback loop from multiple microphones in the source room. By controlling the incident sound field at the element boundary, a flat and spatially uniform excitation spectrum, which is not affected by the sending room modes, can be created (see e.g. Bravo et al. [34]). In combination with the receiving room independent laser vibrometry approach, the genuine sound reduction index $R$ of the building element can be determined, without the disruptive effects of the room acoustics of source and receiving rooms at low frequencies.

\section{Acknowledgements}

N.B. Roozen acknowledges support of the European Commission, Marie Curie Grant, FP7-PEOPLE-2011-IEF, Grant Agreement Number PIEF-GA2011-298278, Project acronym PAM, Project title "the Physics of Acoustic Materials". 


\section{Appendix A. Relation between the reverberation time and damp- ing descriptors.}

For systems characterized by an exponentially decaying impulse response, with decay time $\tau$, the decay of the vibrational energy of the mechanical system is often described in terms of the loss factor $\eta$ :

$$
E(t)=E_{0} e^{-\eta \omega T}
$$

where $\eta \omega=\frac{1}{\tau}$ is the decay constant. Cremer, Heckl and Ungar ([32], section III.4) proposed a relation between the loss factor $\eta$ of a structure, and its reverberation time $T_{\text {struct }}$, where $T_{\text {struct }}$ is the time required for the structure to dissipate its vibrational energy to one millionth of its initial value, as in room acoustics:

$$
\eta=\frac{\ln \left(10^{6}\right)}{\omega T_{\text {struct }}} \approx \frac{2.2}{f T_{\text {struct }}}
$$

As $T_{\text {struct }}$ is the time required for the structure to dissipate its vibrational energy to one millionth of its initial value, it is clear that $e^{\eta \omega T_{\text {struct }}}=10^{6}$, from which Eq. A.2 can be derived. The incorporation of a complex speed of sound results in a complex wavenumber $k$

$$
k=\frac{\omega}{c}=\frac{\omega}{c_{0}(1+\mathrm{i} \xi)}=\frac{\omega}{c_{0}\left(1+\xi^{2}\right)}(1-\mathrm{i} \xi) \approx \frac{\omega}{c_{0}}(1-\mathrm{i} \xi)
$$

According to the modal theory of sound in enclosures (see [26], or for a basic introduction see [33]), the sound pressure evolution inside a rectangular room after a source emitting a pure tone is switched off can be described by

$$
p(x, y, z, \omega)=\sum_{l m n} A_{l m n}(x, y, z, \omega) e^{\mathrm{i} \omega_{l m n} t} e^{-\xi_{l m n} \omega_{l m n} t}
$$

where $A_{l m n}(x, y, z)$ is the amplitude of a given mode at a certain frequency and location $(x, y, z)$, given by

$$
A(x, y, z, \omega)=\frac{B_{l m n} \cos \left(k_{x} x\right) \cos \left(k_{y} y\right) \cos \left(k_{z} z\right)}{\left[\left(\omega / \omega_{l m n}-\omega_{l m n} / \omega\right)^{2}+\left(1 / \xi_{l m n}\right)^{2}\right]^{1 / 2}}
$$

The indices $l, m$, and $n$ denote the number of maxima of the normal modes in $x-, y-$, and $z-$ directions, respectively. The constant $B_{l m n}$ depends on the mode shape and the location of the source and its properties. Assuming that 
one mode is dominant in the frequency range around its natural frequency, the evolution of the energy $E(t)$ can be described as:

$$
E(t) \propto\left|A_{l m n}(x, y, z, \omega)\right|^{2} e^{-2 \xi_{l m n} \omega_{l m n} t}
$$

The acoustic reverberation time $T_{60}$ is thus related to the ratio of the imaginary part over the real part of the speed of sound, $\xi$, as follows:

$$
\frac{E\left(t=T_{60}\right)}{E(t=0)}=e^{-2 \xi_{l m n} \omega_{l m n} T_{60}}=10^{-6}
$$

so that

$$
\xi_{l m n}=\frac{\ln \left(10^{6}\right)}{2 \omega T_{60}} \approx \frac{1.1}{f T_{60}}
$$

Note the subtle difference by a factor 2 in the equation for $\eta$ and $\xi$, given in Eq. A.2 and Eq. A.8, respectively.

A fully accurate characterization of damping requires specifying the damping constant for each mode separately and calculating the resulting sound field as a combination of all modes. In this work, although mode-independent damping was assumed, i.e. $\xi=\xi_{l m n}$, frequency dependence was included via damping parameter $\xi$.

Figure A.20 shows the values for $\xi$ as function of frequency that result from the measured $T_{20}$ reverberation time, for the lightweight wall case studied in this paper.

\section{References}

[1] International Organization for Standardization ISO 717-1: Acoustics. Rating of sound insulation in buildings and of building elements - Part 1: Airborne sound insulation, 2013. 


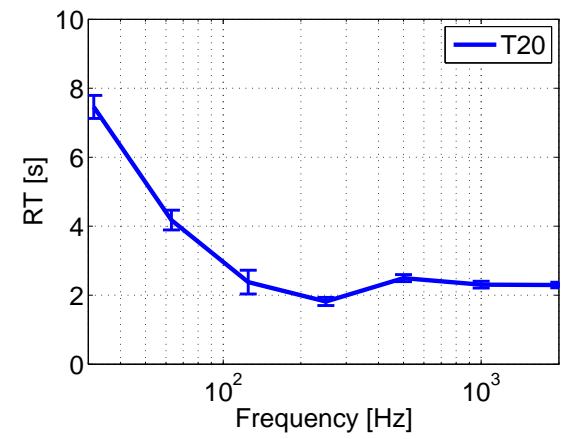

(a)

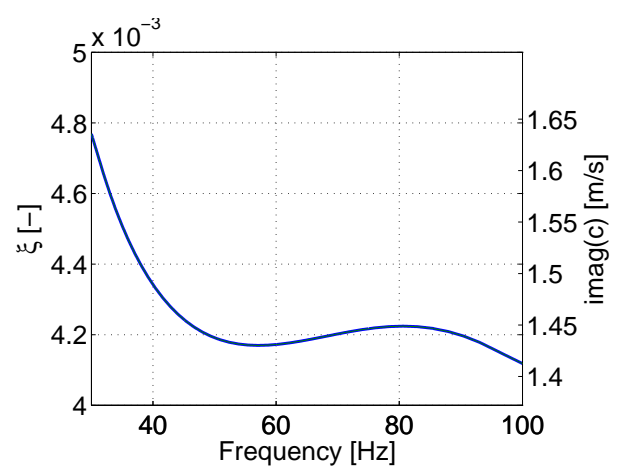

(b)

Figure A.20: Measured reverberation time and resulting damping parameter $\xi$. a) T20 reverberation time (taken from Fig. 13(b)]. b) damping parameter $\xi$ and imaginary part of the speed of sound, interpolated to obtain narrow band frequency resolution.

[2] International Organization for Standardization ISO 10140: Acoustics. Laboratory measurement of sound insulation of building elements - Part 2: Measurement of airborne sound insulation and Part 4: Measurement procedures and requirements, 2010.

[3] W. Kropp, A. Pietrzyk, T. Kihlman, On the meaning of the sound reduction index at low frequencies, Acta Acustica, Vol. 2, 1994, pp 379392

[4] A. Osipov, P. Mees, G. Vermeir, Low-frequency airborne sound transmission through single partitions in buildings, Applied Acoustics 52 (3-4) (1997) 273-288.

[5] A. Dijckmans, G. Vermeir, Numerical investigation of the repeatability and reproducibility of laboratory sound insulation measurements, Acta Acustica united with Acustica 99 (3)(2013) 421-432.

[6] E. Reynders, Parametric uncertainty quantification of sound insulation values, Journal of the Acoustical Society of America 135(4)(2014) 19071918.

[7] P. Santos, A. Tadeu, A note on the acoustic insulation between twodimensional acoustic spaces at low frequencies, Journal of Sound and Vibration 261 (2003) 185-191 
[8] V. Hongisto, J. Keranen, M. Kylliainen, J. Mahn, Reproducibility of the present and the proposed single-number quantities of airborne sound insulation. Acta Acustica united with Acustica 98, 811-819 (2012).

[9] V. Wittstock, On the uncertainty of single-number quantities for rating airborne sound insulation. Acta Acustica united with Acustica 93 (2007) 375-386.

[10] D.B. Pedersen, J.Roland, G.Raabe, W.Maysenhölder, Measurement of the low-frequency sound insulation of building components, Acta Acustica united with Acustica 86 (3)(2000) 495-505.

[11] C. Hopkins, P. Turner, Field measurement of airborne sound insulation between rooms with non-diffuse sound fields at low frequencies, Applied Acoustics 66 (2005) 1339-1382

[12] P. Castellini, M. Martarelli, E.P. Tomasini, Laser Doppler Vibrometry: Development of advanced solutions answering to technology's needs, Mechanical Systems and Signal Processing, Vol. 20, Issue 6, August 2006, pp 1265-1285.

[13] G.M. Revel, G.L. Rossi, Sound power estimation by laser Doppler vibration measurement techniques, Shock and Vibration, Vol. 5 (5-6) (1998) 297-305.

[14] O.E. Kaiser, S.J. Pietrzko, M.Morari, Feedback control of sound transmission through a double glazed window, Journal of Sound and Vibration 263 (2003) 775-795.

[15] C. Churchill, C. Hopkins, Prediction of the dynamic properties of a cross laminated timber plate from an investigation of the eigenmodes using a scanning laser vibrometer, AIA-DAGA Merano, 2013.

[16] International Organization for Standardization ISO 3741: Acoustics Determination of sound power levels and sound energy levels of noise sources using sound pressure, 2010.

[17] M. Vorlander, Revised relation between the sound power and the average sound pressure level in rooms and consequences for acoustic measurements. Acta Acustica united with Acustica, 81, 332-343, 1995. 
[18] Q. Leclère, Multi-channel spectral analysis of multi-pass acquisition measurements, Mechanical Systems and Signal Processing 23 (2009) 1415-1422, doi:10.1016/j.ymssp.2008.12.002.

[19] N.B. Roozen, Q. Leclère, M. Rychtáriková, C. Glorieux, A global error estimator for the uncertainty of a multi-channel spectral analysis, Applied Acoustics (2014), http://dx.doi.org/10.1016/j. apacoust.2014.06.007, open access: https://lirias.kuleuven.be/ bitstream/123456789/458822/3/Globalerrorestimator.pdf

[20] J.S. Bendat, A.G. Piersol, Engineering Applications of Correlation and Spectral Analysis, Wiley-Interscience, NewYork, 1980.

[21] G.H. Koopmann, H. Benner, Method for computing the sound power of machines based on the Helmholtz integral, Journal of the Acoustical Society of America, 71 (1), 1982.

[22] F. Fahy. Sound and Structural Vibration: Radiation, Transmission and Response. Academic Press, London (1985).

[23] J.S. Lamancusa, Numerical optimization techniques for structuralacoustic design of rectangular panels, Computers \& Struct 1993

[24] P.K. Banerjee, R. Butterfield, Boundary element methods in engineering science. McGraw-Hill, London, 1981.

[25] O.C. Zienkiewicz, The finite element method in engineering science. McGraw-Hill, 1971.

[26] N.B. Roozen, L. Labelle, D. Pelegrín-Garcíaa, M. Rychtáriková, C. Glorieux, Q. Leclère, Determination of the sound power by means of scanning laser vibrometry, In: Proceedings of Internoise 2013, Innsbruck, Austria.

[27] A.G. Piersol, Use of coherence and phase data between two receivers in evaluation of noise environments, Journal of Sound and Vibration 56(2), 215-228, 1978.

[28] F. Jacobsen, T.G. Nielsen, Spatial correlation and coherence in a reverberant sound field, Journal of Sound and Vibration 118(1), pp 175-180, 1987. 
[29] N.B. Roozen, H. Muellner, L. Labelle, M. Rychtáriková, C. Glorieux, Influence of panel fastening on the acoustic performance of light-weight building elements: study by sound transmission and laser scanning vibrometry, Journal of Sound and Vibration, 2015, DOI: http://dx.doi.org/10.1016/j.jsv.2015.02.027, open access: https://lirias.kuleuven.be/bitstream/123456789/484064/ 3/JSVInfluenceofpanelfasteningRev3a.pdf

[30] International Organization for Standardization ISO 3382: Acoustics Measurement of room acoustic parameters, 2009.

[31] F.T. Agerkvist, F. Jacobsen, Sound power determination at low frequencies, Journal of Sound and Vibration 166(1), pp 179-190, 1993.

[32] L. Cremer, M. Heckl, E.E. Ungar. Structure-borne sound, SpringerVerlag 1988

[33] L.E. Kinsler, A.R. Frey, A.B. Coppens, J.V. Sanders: Fundamentals of Acoustics,4th Edition, 2000

[34] T. Bravo, S.J. Elliott, Variability of low frequency sound transmission measurements, J. Acoust. Soc. Am. 115 (6), June 2004 